\title{
Multi-dimensional overall regulatory modes and threshold values for water cycle of the Haihe River Basin
}

\author{
GAN Hong ${ }^{1 *}$, WANG Lin ${ }^{1}$, CAO YinBai ${ }^{2}$, YOU JinJun ${ }^{1}$, GAN ZhiGuo ${ }^{1}$, QIN ChangHai ${ }^{1}$, \\ HE Shan ${ }^{2} \&$ XU Kai ${ }^{1}$ \\ ${ }^{1}$ State Key Laboratory of Simulation and Regulation of Water Cycle in River Basin, China Institute of Water Resources and Hydropower \\ Research, Beijing 100038, China; \\ ${ }^{2}$ Haihe Water Conservancy Commission, Ministry of Water Resources, Tianjin 300170, China
}

Received March 14, 2012; accepted July 13, 2012; published online December 28, 2012

\begin{abstract}
In this study, a multi-dimensional critical regulatory criteria and decision-making mechanism based on the scientific cognition of multi-dimensional attributes and characteristics of the water cycle was proposed. This system was functioned by deeply discriminating the nature-society binary characteristics of the five-dimensional characteristics of the water cycle system of the Haihe River Basin (water resources, economy, society, ecology, and environment) under the influence of high-intensity human activities and hydrological changes and by analyzing the organic interactive relationships between the five dimensions and their overall effect on the water cycle. A GDP calculation model was constructed in this study by adjusting the water environment for water resources, after which five-dimensional normalization objective functions were established for multi-objective analysis to carry out trade-off analysis of multi-dimensional regulatory indexes. In addition, synergetic theory, entropy theory and dissipation structure theory were introduced to construct an evaluation model for multi-dimensional regulatory schemes. A water cycle multi-dimensional critical overall regulatory model system was also established. This system consisted of a multi-objective macroeconomic model (DAMOS), water resource allocation model based on rules (ROWAS), evaluation model for WEDP (EMW) and multi-dimensional regulatory scheme evaluation model (SEAMUR) as the main body. To address the national demands faced by the Haihe River Basin as a result of combinatorial schemes for different hydrological series and water amounts diverted by the south-to-north water diversion project, this study adopted a hierarchy progression method to set up the technologies, investigated multi-dimensional overall regulatory methods, proposed an overall regulation threshold value for the water cycle of the Haihe River Basin, and recommended corresponding five-dimensional regulatory schemes.
\end{abstract}

water cycle, multi-dimensional regulation, mode, threshold value, Haihe River Basin

Citation: Gan H, Wang L, Cao Y B, et al. Multi-dimensional overall regulatory modes and threshold values for water cycle of the Haihe River Basin. Chin Sci Bull, 2013, 58: 3320-3339, doi:10.1007/s11434-012-5537-9

Due to population growth, rapid economic development and the effects of natural conditions on water resources, water shortage, water pollution and ecological degradation have become major factors affecting national resources and environmental safety. Among the ten first-grade river basins in China, the Haihe River Basin has suffered the most serious environmental problems. In addition, groundwater overexploitation, difficulty maintaining of instream water consumption, water environmental degradation, surface eco-

*Corresponding author (email: ganhong @iwhr.com) logical degradation, seawater intrusion and ground subsidence pose threats to regional sustainable development in the basin [1]. Indeed, a critical state currently exists in water resource development and use. The reproducible maintenance of the water cycle in the region is directly related to the sustainability and fairness of economic and social development, as well as the stability of the ecological system and water environmental system. Water resources, the economy, environment, society, and ecology are mutually associated with the basin and inter-convertible; accordingly, dramatic changes in one of these attributes will affect their 
own service functions as well as those of other attributes, and may produce irreversible damage. Therefore, responsible use of limited water resource necessitates that these five attributes be considered. Exploring regulatory modes of the water cycle in water shortage areas under the influence of high-intensity anthropogenic activities that will result in competitive synergy and high efficiency, as well as facilitating the water cycle to develop toward a benign alternating direction are key factors that the water conservancy will be devoted to for the foreseeable future.

\section{Theory of multi-dimension regulation on water cycle}

Multi-dimensional critical regulation of the water cycle needs to achieve overall analysis and reasonable regulation of the water cycle of the river basin, as well as factors that affect this cycle such as nature, society, the economy, and ecology. Currently, investigations of the five-dimensional system of the water cycle are still at the stage of turning from qualitative to quantitative. Because of the many difficulties associated with scientific regulation and prediction based on conversion of the multi-dimensional effects and quantitative analysis, there is an urgent need for advances in the planning theory, decision-making methods and quantitative representation to realize the reasonability of decision-making. The Haihe River Basin covers a large area that contains multiple reservoir groups and involves many water sources such as surface water, groundwater, water diverted from external river basins, and reclaimed water. In addition, the basin contains industrial, urban, agricultural and ecological users. Accordingly, the basin includes multiple decision-making groups associated with different areas and different departments to address a variety of problems such as impacts on the regional economy, environment and society by different development programs and management modes. The sustainable social and economic development of the river basins requires that the water resources be used sustainably and can be regenerated benignly. Based on the current decreasing river flow, groundwater level, amount of water flowing to the sea and quality of the water environment; it is necessary to implement scientific regulation of the water cycle system of the river basin [2]. Therefore, river basin regulation based on multi-dimensional attributes involves studies of multi-objective decision-making methods, water resource allocation, environmental economic value evaluation, and many other fields.

The multi-objective decision-making method has been extensively applied since being introduced to the water resource field. This method includes optimal allocation of water resources, water resource carrying capacity analysis, reservoir scheduling, water sand joint scheduling, water resources management, water ecological regulation and water pollution prevention and regulation and has obtained a good application effect [3-6]. In foreign countries, the multi-objective method is currently primarily used for handling problems that are relatively clear in water resource competitive relationships; therefore, it puts more emphasis on basic theory research in specific application processes. Yapo et al. [7] from the University of Arizona put forward the MOCOM-UA algorithm (Multi-Objective Complex Evolution) as an expansion algorithm of the SCE-UA (Mixed Shuffle Complex Evolution) objective global optimization algorithm, which can effectively solve multiobjective global optimization problems. Merino et al. [8] further generated the fuzzy compromise programming method with the precedence order on the basis of fuzzy comprehensive planning and the multi-attribute decision-making method under predominant attributes that not only kept the characteristics of the fuzzy comprehensive programming method, but also gave the decision-maker great flexibility in designating the objective proportion. Andrea et al. [9] developed a comprehensive and participatory planning program that combined traditional technologies with subjective decisions and preferences well, using the multi-objective decision-making support system as a tool to bridge the gap between theory and practice.

Research regarding water resource allocation began with reservoir scheduling and optimal allocation of water in irrigation areas. Since then, water resource allocation under multi-objective decision-making constraint conditions has become the focus of many studies of water resource allocation. Babel et al. [10] put forward the water resource optimization allocation model under the water demand constraint conditions of competitive users, in which the reservoir scheduling optimization module (ROM), economic optimization analysis module (EAM) and water amount allocation module (WAM) were covered. Andrew et al. [11] put forward the water amount allocation model using a mathematical model based on nonlinear programming to meet the demands of multiple stages and users.

The core of environmental and economic accounting evaluation of water resources is the value evaluation module, which includes calculation of the water resource depletion value, water ecological degradation value and water environment protection cost to adjust the GDP. Owing to the complexity of contents and controversy associated with estimation methods, the System of Environmental and Economic Accounting for Water (SEEAW) issued by the United Nations explicitly stated that there be no discussion on the adjustment of macroeconomic aggregates caused by depletion and degradation due to complexity of the adjustment; however, practices in China prove that research in this area is very necessary in terms of water-related issues. The water resource depletion value mainly involves accounting for the amount of water resource depletion and the water resource value. Lu et al. [12] clearly defined the amount of water resource depletion through water cycle process analysis and carried out related practical research in 
China. Currently, the international water resource value focuses on investigation of the water economic value, with detailed exploration of relevant methods [13,14], but the water economic value only reflects the price of the demanding side, while the market price actually reflects the price of various value-attributes of the water resource. Recently, a theoretical discussion of the water resource value has entered the in-depth cognition stage [15-17]. To determine the water ecological degradation value, ecological service value evaluations including the water resource were carried out [18,19], while Wang and Yu adjusted the GDP in an attempt to solve the ecological degradation and environmental protection cost problems, but did not consider the resource depletion problem [20]. Indeed, there has not been a system practically applied to adjustment of the GDP to solve the problems of water resource depletion, water ecological degradation and cost of water environment protection.

Some achievements have been made in the large-scale water resource regulation theories and methods for river basins, but multi-dimensional critical regulation theory investigating the multiple layers of the complex relationships among the economy, society, ecology, environment, and water cycle as a whole is not yet mature. Although the academic circle has conducted some studies of the multi-dimensional attributes and multi-objective regulation of water resources [21-24], there is still no comprehensive analysis tool based on the water cycle that also considers various objectives. This is reflected as follows: (1) The existing regulation objectives are focused on maximization of the water supply economic benefit or ecological benefit, and not enough attention is given to collaborative study of the five-dimensional regulatory objectives. (2) Investigations of regulation simulation and optimization collocation methods have primarily been geared toward economic and ecological demands, and lack five-dimensional vector demand integrative balancing and regulatory modes as well as methods that consider the fairness and efficiency of water resource use. (3) It is still difficult to use simulation methods to exactly express the relationships among water resources, the economy and society, and there is a need to embed the simulation of water resource systems into simulation of the water cycle process.

In this study, comprehensive simulation of the water cycle of the Haihe River Basin and its accompanying processes were used as the basis and the highly efficient use of this water resource was used as the core to develop evaluation criteria, regulatory modes, threshold standards, and scheme comparison of the multi-dimensional overall regulation of the water cycle of the river basin using the regulation threshold value determination method of key regulation indexes of the river basin proposed. (1) Regarding the optimization objective, the single objective of achieving balance between supply and demand of water resource and the amount of water was turned to sustainable development of the regional water resources, economy, society, ecology, and environmental coordination to quantify the competitive and restrictive relationships between the objectives. (2) Regarding the regulation method, research was conducted to combine the macroeconomic quantitative analysis and reasonable allocation of water resources in the river basins to strengthen investigations of the dynamic balance of interdependence among water resources, the economy, society, ecology, and the environment so as to combine the optimization technology and simulation technology. (3) Regarding the scheme comparison, the system entropy and synergetic theory were used to comprehensively compare and evaluate the five-dimensional system of the water cycle and deepen research regarding the five-dimensional competitive coordination research regarding optimal water resource allocation.

\section{Methodology and models}

\subsection{Regulation technical framework}

(i) Water cycle multi-dimensional attributes and regulation connotation. High-intensity human activities continually change the movement processes of rainfall, surface water, soil water and groundwater in the water cycle of the Haihe River Basin, causing it to form obvious nature-society binary characteristics, and leading to significant changes in the five-dimensional relationships: as the economic scale continues to expand, the economic attributes of the water cycle increases. Anthropogenic disturbances and changes in hydrological conditions cause reductions in water cycle stability and weakening of the resource attributes. Water environmental degradation causes reduction of the water ecological service functions and decline of the ecological attributes, as well as decreased water self-purification and environmental attributes. The contradictions between supply and demand of the water resources have become increasingly prominent, and the social attributes are changed dramatically. Thus, the overall regulation of the water cycle requires consideration of the basic attributes and connotation of the five dimensions, which determine the direction of five-dimensional regulation. This study also selected two characterization indexes from each dimension to reflect the characteristics of each dimension through comprehensive analysis.

The direction for resource regulation focuses on water cycle stability or reproducibility maintenance. This includes the space-time quantity and quality and reproducibility of the water resource system, requiring that human activities do not excessively interfere with links of the water cycle such as runoff production, confluence, infiltration, replenishment, and discharge. The direction for economic regulation is to divert water resources from low-efficiency and low-benefit industries to high-efficiency and high-benefit industries. The purpose of this direction is to maximize the 
water use efficiency and benefit under current basic social ethics and philosophical frameworks. The water consumption for GDP per capita and GDP per $10000 \mathrm{CNY}$ were selected to represent the level of economic development and water use efficiency, respectively, with the unit indexes used for comparison between regions and compliance with international standards. The direction for society regulation is to guarantee basic water consumption needs for vulnerable groups and public welfare industries. This direction primarily includes: (1) Balance between survival and development, which is mainly to guarantee the balance relationship between grain security and economic development. (2) Fairness between regions. (3) Fairness between national economic industries. (4) Fairness between urban and rural areas. The grain output per capita and ratio between rural and urban domestic water consumption per capita (rural/urban) are used to express the grain output scale and gap between rural and urban domestic water consumption. The direction for ecology regulation focuses on system continuity to ensure the stability and recovery of key ecological systems. Between the appropriate ecological water demand and minimum ecological water demand of the ecological system, the balance will be found among ecological service functions and economic and social service functions to achieve a win-win situation. In the Haihe River Basin, this is reflected in maintenance of a basic amount of water flowing to the sea and instream ecological water consumption. The direction for environmental regulation focuses on maintaining good quality for the region. Water resource use shall be prevented from causing harm to health and biological and ecological systems as well as from damaging landscapes. Environmental harm is also a great challenge to social fairness. In this study, environmental harm is characterized based on the COD of sewage discharged to the river and the qualification rate of water function areas.

The essence of regulation is to guide the natural system that we live in toward rational and allowable threshold values and away from the critical state of collapse through rational regulation over anthropogenic activities. Water cycle multi-dimensional regulation is designed to adjust the dimensions toward ideal objectives above the critical points and within the rational threshold value to seek competition and harmonious balance among the five dimensions so that the water cycle system is maintained in the most suitable state for human scientific and economic development.

(ii) Macro regulation criteria and decision-making mechanism. The overall regulation of the multi-dimensional water cycle is designed to maintain water resources in a harmonious state rationally and effectively through structural conversion and complementary relationships among the five dimensions. It shall follow the four macro regulation criteria and the five-dimensional decision-making mechanism.

Macro regulation criteria: (1) The speed of development and use of water resources should not exceed the reproduci- bility rate, or use of the water resource shall take the reproducibility as the threshold. (2) When the speed of development and use exceeds the speed of reproducibility, the water resource demands shall not exceed the speed of development and use of renewable alternative resources (such as recycling of sewage and floodwater, inter-basin water diversion, etc). (3) The emission of pollutants shall not exceed the self-purification capability of the water environment. (4) The maximization of efficiency and benefit shall be pursued under the fair framework as much as possible.

Five-dimensional decision-making mechanism: (1) The first dimension is a resource decision-making mechanism based on water balance to ensure artificial runoff water consumption does not exceed the allowable runoff water consumption. (2) The second dimension is an economic decision-making mechanism based on benefit that is designed to optimize the water allocation scheme to obtain the maximum comprehensive environmental economic benefit through analysis and comparison of economic benefits and water loss for different water usages. (3) The third dimension is a social decision-making mechanism based on fairness to coordinate the contradictions associated with survival and development between strong groups and weak groups while guaranteeing grain security, coordinating urban and rural development speeds, and decreasing the gap between urban and rural water consumption per capita. (4) The fourth dimension is an ecological decision-making mechanism based on maintaining good ecological functions to avoid interference and damage to regional ecological systems and maximize the value obtained by deducting the loss formed because of decreased ecological system service value during artificial water consumption from the newly-added ecological service value after regulation of the amount of artificial water. (5) The fifth dimension is an environmental decision-making mechanism based on maintaining water functions to induce the control section to meet the water environmental and water functional zoning requirements so as to ensure that the treatment and emissions of the river basin pollution load meet standards and to maintain the self-purification capability of the regional water environment.

(iii) Over-regulation framework. The water cycle regulation multi-dimensional overall regulation must include objective decomposition optimization, scheme setting and evaluation, simulation calculation and benefit analysis and countermeasure formulation under the five-dimensional framework to enable investigation and establishment of a multi-dimensional overall regulation analysis technical framework, which includes the following four layers (Figure 1). (1) Objective decomposition optimization layer. This layer combines national objectives and regional development planning based on analysis of the water cycle multidimensional attributes to determine the ideal points and scope of regulation, discriminate the value conversion relationships among dimensions, use the reproducibility 
maintenance, economic and scientific development and ecological environmental protection collaborative development modes of the water cycle system, improve the water resource use rate and guarantee ability, adopt a three-layer progression method to construct scheme sets, put forward multi-objective optimization regulatory schemes under the economic and social development trend, and clarify the relationships between water consumption and economic, environmental, and ecological effects. (2) Scheme evaluation layer. This layer uses the information entropy, dissipative structure theory and synergetic theory to compare and analyze multi-dimensional regulatory schemes, determine the macro regulation characterization indexes (order parameters) and proportion according to the five-dimensional regulation criteria and decision-making mechanism, construct a multi-dimensional regulation evaluation model to perform scheme evaluation, and put forward an overall regulation threshold value. (3) Simulation effect analysis layer. This layer is designed to simulate the processes of key regulatory schemes, verify the feasibility of regulation objectives, conclude the gross control scheme, and analyze the relevant ecological and environmental effects. (4) Regulation measure layer. This layer proposes a water resource sustainable utilization countermeasure system based on the simulation effects, and provides technical support regarding overall regulation of the water cycle for the decision-making layer.

\subsection{Model and method}

(i) Objective function. Overall regulation of the multidimensional system requires construction of an overall objective function that can objectively reflect the effects of each dimension on the basis of the existing level of knowledge. The regulation objective determines whether the decisions are inclined toward economic and social development or ecological and environmental protection, which relates to the value theory, results of regulation and weighing standard of the regulation.

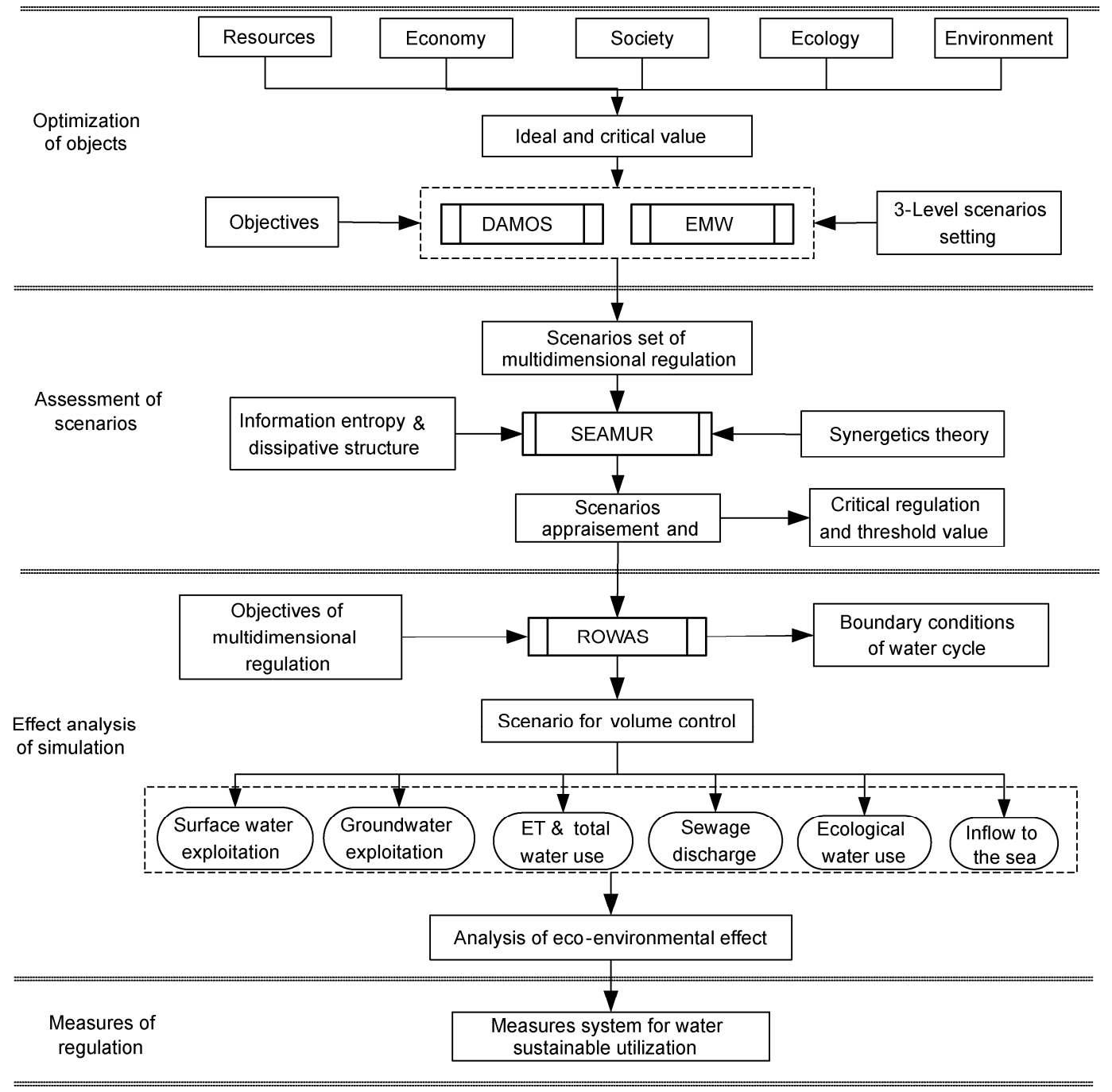

Figure 1 Framework of multi-dimensional overall regulation on water cycle. 
(1) Five-dimensional normalization objective function. Attempts were made to realize the rational five-dimensional normalization objective function through research into the internal mechanism of water cycle multi-dimensional attributes, gross control principles and standards, threshold index sets, regulatory mode construction, scheme evaluation, multi-objective analysis, etc. To maximize the comprehensive benefit and minimize the differences between regions, this function represents the resource, economy, society, ecology, and environment based on economic value and sums up the scalar quantity to realize unification of the multi-dimensional amount. The five-dimensional normalization objective function can be expressed by the following equation:

$$
\begin{aligned}
\operatorname{Cobj}= & f[\max \operatorname{GDP}(t, d), \operatorname{minCOD}(t, d), \max \operatorname{FOOD}(t, d), \\
& \min \operatorname{OvEX}(t, d), \max \operatorname{ECOW}(t, d)],
\end{aligned}
$$

where, GDP represents the per capita gross domestic product as the economic development objective; COD represents the per capita chemical oxygen demand as the water environment comprehensive evaluation objective; FOOD represents the per capita grain occupancy as the social security index; OVEX represents the over-exploitation control as the water resource reproducibility maintenance objective; ECOW represents the river way ecological environment water consumption as the ecological and environmental protection objective; $t$ represents time, $d$ represents the district; $f$ represents the process of value conversion and normalization of each objective. Because the objective functions for water resource, economy, society, the environment and ecology take groundwater over-exploitation, GDP per capita, grain output per capita, COD of water flowing to the river, and river way ecological water quantity as the basic units, the objective values were first converted into economic values during multi-objective analysis, after which non-dimensionalization processing was performed, making the multi-objective analysis possible.

(2) WEDP maximum objective function. In the traditional national economic accounting system, the gross domestic product (GDP) provides the comprehensive measurement scale for the economic situation of a country; however, it has obvious defects in reflecting the relationship between economy and the environment. This is because the GDP does not reflect the effects of the environment on the economic process or the impact that the economic process has on the environment. The integrated system of environmental and economic accounting (SEEA) issued by the United Nations incorporates resources and environmental factors into the statistical accounting scope. SEEAW carried out in China combines the information of water resources and the economy through setting up physical water accounting, economic accounting and integrated water accounting. The water resource depletion value [25], water ecological degradation value and water environmental degradation value
[26] caused by socio-economic growth can be quantified through the accounting system in China. The comprehensive information by China accounting system reflects relations among water resource development and utilization, economy and environment. Based on SEEAW, this study analyzed the water resource depletion value, water ecological environmental degradation value and water environment protection expenditure for the Haihe River Basin and put forward the maximization objective of the adjusted GDP by water resources depletion and water environmental degradation (WEDP), which is defined as follows:

$$
\max (\mathrm{WEDP})=\max \left(\mathrm{GDP}-C_{\mathrm{wrde}}-C_{\text {wede }}-C_{\text {wepr }}\right),
$$

where, WEDP represents the GDP after adjustment of the water resource environment; GDP represents the gross domestic product; $C_{\text {wrde }}$ represents the water resource depletion value; $C_{\text {erde }}$ represents the water ecological degradation value; $C_{\text {wepr }}$ represents the water environmental protection expenditure.

(ii) Tradeoff analysis of regulation indexes. The interactive correlation form of the five-dimensional attributes of the water cycle system is structurally manifested as all kinds of nonlinear relationships and as the multiple exchanges of material, energy and information in content. Effective control on water-related human activities and regulation on water cycle will induct the water resources system run to better state [27]. The Haihe River Basin is a severely waterdeficient area; therefore, there is significant competition for water resources. However, the corresponding multi-dimensional regulation indexes restrain each other. As a result, changes in the systematic environment drive the water cycle from one relatively balanced state to another. However, the system could maintain overall integrity and operational stability spontaneously when it undergoes small internal and external changes if it keeps in relative equilibrium. Therefore, investigation of the dimensions under a certain balance state is important to promotion of the transformational relationship among system balances, namely the exchange ratio of dimensions.

To clarify the exchange ratio of dimensions under a specific balance state, the basic regulatory scheme was first determined according to the recommended scheme for comprehensive water resources planning in the Haihe River Basin. This scheme includes the regional transpiration evaporation capacity (ET), water quantity, external water diversion amount, and other boundary conditions. To enable convenient comparative analysis, the economic effect was used to analyze the impact of changes in the indexes of each dimension on the GDP. During analysis, other variables were fixed to study the sensitivity of changes in the indexes of a certain dimension influencing the GDP, compare the influence of changes in the regulation indexes such as the amount of water flowing to the sea, groundwater overexploitation, and agriculture water consumption on the GDP, and establish the functional relationships between changes 
in the index of each dimension and the GDP. Using GDP as the benchmark, the exchange ratio between each index was quantitatively analyzed to provide a uniform quantization basis for analysis of the effect of water exchange between each dimension [28].

(iii) Regulatory model system. To clarify the interactive relationship between water cycle multi-dimensional attributes and their regulation connotations, standards, objectives, and technical framework, the multi-dimensional overall regulatory model system was established with the multiobjective macroeconomic model (DAMOS), water resource allocation model based on rules (ROWAS), evaluation model for WEDP (EMW) and multi-dimensional regulatory scheme evaluation model (SEAMUR) as the main body to enable five-dimensional balanced regulation of the Haihe River Basin through the generation of scheme sets, system analysis and verification, objective decomposition and normalization, and scheme evaluation and comparison.

(1) Multi-objective macroeconomic model (DAMOS). This model determines the economic and social development mode and its investment and water supply composition through multi-objective tradeoff, ascertains the evolution direction of ecology, the environment and water cycle, and coordinates the contradictory and competitive relationships between dimensions through capital allocation and deployment of the water supply. The DAMOS model is composed of multi-objective balance regulation, macro economy, water resource balance, the environment, ecology and other basic modules. The economic module is divided into an input-output analysis sub-module and water demand calculation sub-module, which determines the social and economic scale and the developmental proportion of each industry through input-output analysis and then calculates the relevant water demand through the water demand submodule. The water resource module contains a regional water balance sub-module (ET regulation) to control the regional water balance and calculate the ET according to the water demand analysis. The water resource balance submodule calculates the water supply according to regional water characteristics and the water supply capacity of the water conservancy project. The ecological environment analysis module processes the water consumption of the ecological environment, controls pollutants flowing to the river and interacts with the social and economic development module. The social development module is used to balance the level of regional development and adjust the industrial development speed. The multi-objective balance module coordinates the relationships between each module, establishes objective equations, completes the multi-objective non-inferior solution calculation, and outputs the multi-objective macro-economic forecast analysis results. The multi-objective balance module establishes the gross domestic product, industrial and agricultural output value, and proportionate relationships between consumption and accumulation under the existing situation and forecasting sta- tus through the macro-economic module. In the optimization process, the guiding principles of water-saving plans are fully considered to optimize the industrial structure, planting structure and water consuming structure. Additionally, the results are combined with the social development module to ensure regional and industrial fairness. During optimization, the water demand sub-module is used to calculate the water demand, while the sewage treatment cost for investment is used to reflect the sewage treatment cost, the groundwater over-exploitation and amount of water flowing to the sea are used to weigh the ecological and environmental conditions, and the objectives for water resource, society, the environment, ecology, and the economy are combined to maximize the comprehensive economic benefit. The objective function is shown in eq. (1).

(2) Water resource allocation model based on rules (ROWAS). This model is mainly used to realize the reasonable allocation of water under a wide variety of engineering technical constraints and system operational rules and to complete the allocation from water source to users from the layers of time, space and user. Through abstraction and simplification of the water cycle processes, the complex system is converted to a framework meeting the mathematics description after conceptualization processing to realize the modeled simulation for the entire system. The dot elements used in the system conceptualization processing include the calculating units and regulation nodes. The line elements in the system primarily include the water transmission or influence existence in different dot elements. The calculating unit is the central link of system simulation. In general, the water resource zoning nesting administrative region is used as the calculating unit, in which the water resource supply, consumption, and discharge are analyzed. The nodes include key engineering nodes with water diversion and storage regulation functions or water catchment demands and regulation sections.

Based on the dot and line elements described above, the main processes and influence factors of the system are identified to classify and simulate the water resources and water users and establish the water supply, consumption and discharge processes. This framework describes the modes of water movement transformation between the generalized system elements and considers the impact of different water source development and utilization projects. Through conceptualized the dot and line elements, the network node diagram is drawn for the water resource system to describe the relationships among amounts of water in the river basin, as well as to establish a mathematics model reflecting the regional water supply and discharge and conversion relationships for the river basin. The model constructs the calculation module according to the utilization processes of different water sources such as surface water, groundwater, local surface runoff and inter-basin water diversion. The comprehensive results for water resource allocation, such as the system water balance, supply and demand balance, pro- 
ject operation scheduling status and water source development and utilization status are obtained through calculation by the model.

(3) Evaluation model for WEDP (EMW). This model establishes the tradeoff analysis relationships for multidimensional indexes of the material object indexes (water resource depletion, sewage discharge amount, groundwater level and amount of water flowing to the sea) and the value magnitude index (shadow price for water resource, water resource depletion value, water ecological degradation value, water environmental protection expenditure, GDP) from the point of view of the market economy. This model also reflects the water resource depletion value, water ecological degradation value, and water environmental protection expenditure caused at the same time as the increase in GDP, and evaluates the adjusted GDP by water resources depletion and water environmental degradation (WEDP). Finally, the EMW model investigates the maximum social and economic water consumption range of the WEDP, which is taken as the threshold value of the rational development and utilization of water resources in the river basin.

The model is divided into three modules, input-output analysis, water consumption negative-effect analysis, and water resource value evaluation (Figure 2).

The first module is input-output model. Based on a certain industrial structure, this model establishes the relationship between the water resource and national economy and simulates indexes such as the shadow price for water resources under a certain water amount, gross domestic product, industrial water consumption and sewage discharge amount, thus establishing the water resource depletion cost accounting model based on the macroeconomic input-output model. The model then calculates the water resource depletion value [25].

The second module is water consumption negative effect analysis model. This model analyzes changes in indexes such as the groundwater level, amount of water flowing to the sea and water resource depletion amount. The model then establishes the mathematical relationships between each index and water consumption. Among these indexes, the water resource depletion amount refers to the water consumption for economic and social activities that exceeds the development and utilization threshold value, which is the sum of the depletion value of surface water and groundwater. The relationship with the water consumption is expressed as follows:

$$
D_{\mathrm{w}}=\left[\left(U_{\text {out }} \cdot r+U_{\text {in }} \cdot r+T_{\text {out }}\right)-A_{\mathrm{s}}\right]+\left[E_{\mathrm{sg}}-A_{\mathrm{g}}\right]+E_{\mathrm{dg}},
$$

where, $D_{\mathrm{w}}$ represents the water resource depletion value; $U_{\text {out }}$ represents the external water diversion amount; $U_{\text {in }}$ represents the local surface water consumption amount; $r$ represents the water consumption rate, which is equal to the ratio between the water consumption and water use amount; $T_{\text {out }}$ represents the surface water diversion amount; $A_{\mathrm{s}}$ represents the usable surface water resource amount; $E_{\mathrm{sg}}$ and $E_{\mathrm{dg}}$ refer to the shallow and deep groundwater development and utilization amount, respectively; $A_{\mathrm{g}}$ represents the usable groundwater resource amount.

The third one is value evaluation model. This model evaluates indexes such as the resource depletion cost caused by a certain amount of water consumption, ecological degradation value and water environmental protection expenditure. In addition, the model analyzes the negative effects produced during the water consumption process, and further evaluates the net economic benefits of the waterrelated activities of the Haihe River Basin.

$$
\mathrm{WEDP}=\mathrm{GDP}-C_{\text {wrde }}-C_{\text {wede }}-C_{\mathrm{wepr}} .
$$

(4) Multi-dimensional regulatory scheme evaluation model (SEAMUR). This model selects the order parameters

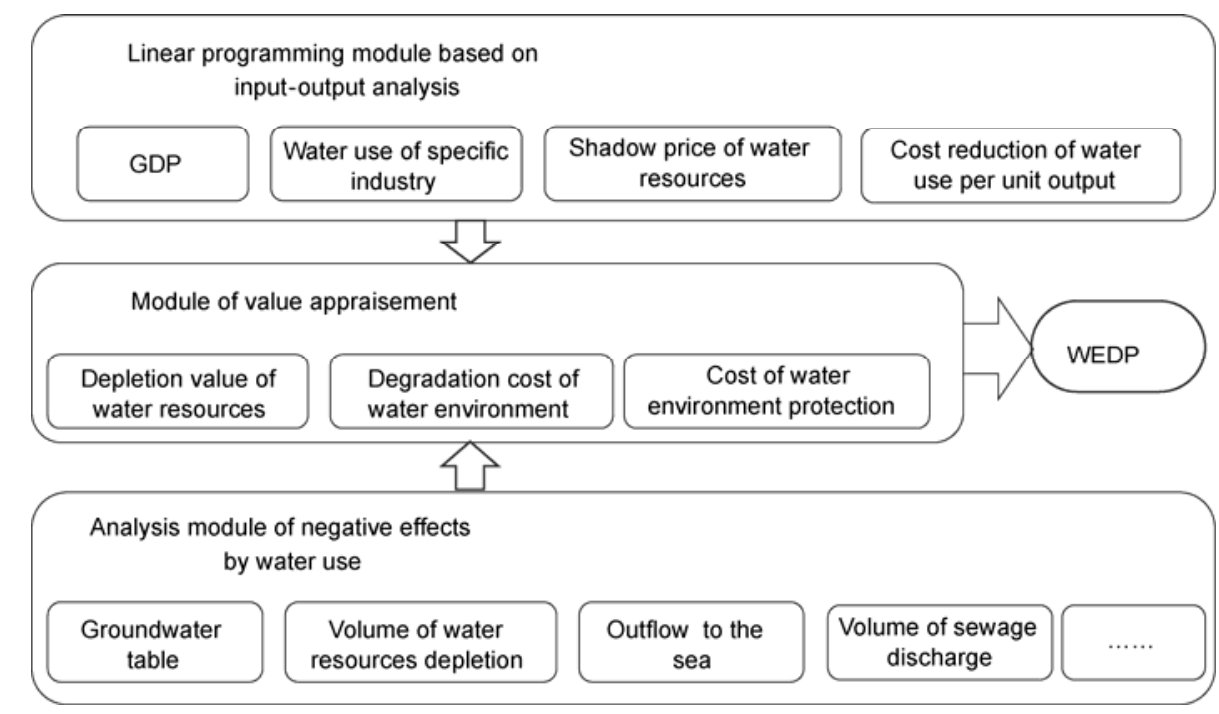

Figure 2 Structure of the EMW model. 
of each dimensional attribute as the evaluation indexes to reveal the synergistic effects of the internal water cycle system based on entropy theory and synergetic theory. This model introduces the information entropy concept to construct the order degree entropy function for the water cycle system and evaluate a single regulatory scheme with the target year as the benchmark, adopts a dissipative structure entropy change and system order relationship, identifies the evolution direction of the water cycle system at the target year, refers to the coordination degree concept, constructs a comprehensive distance function to determine the degree of system coordination and order, quantifies the change in the degree of order of the water cycle system within the regulation period, and reflects the regulatory effect of the serial years of combined regulation (Figure 3) [29].

Single and combined scheme evaluation is based on calculation of the degree of order for each sub-system. The formula selected to calculate the degree of order of the five-dimensional sub-systems is as follows:

$$
\left\{\begin{array}{lc}
U_{j i}\left(e_{j i}\right)=1-\left|\frac{e_{j i}-c}{a_{j i}-b_{j i}}\right|, & i=1,2, \\
U_{j}=\alpha_{j} U_{j}\left(e_{j 1}\right)+\beta_{j} U_{j}\left(e_{j 2}\right), & j=1,2,3,4,5 .
\end{array}\right.
$$

The degree of order of entropy is used to discriminate the evolution direction of the water cycle system for a certain target year, which is calculated as follows:

$$
S_{y}=-\sum_{j=1}^{5} \frac{1-U_{j}}{5} \log _{2} \frac{1-U_{j}}{5} .
$$

The degree of coordination is used to evaluate the degree of harmony associated with the developmental change in the dimensional attributes of the water cycle system using the geometry average method for calculation:

$$
H(t)=\theta * \sqrt[5]{\left|\prod_{j=1}^{5} U_{j}\right|}, \quad \theta=\frac{\operatorname{Min}\left(U_{j}\right)}{\left|\operatorname{Min}\left(U_{j}\right)\right|}, \quad j=1,2,3,4 .
$$

The comprehensive distance of the degree of coordination is used to evaluate the overall coordination status of different target year combined schemes:

$$
\rho\left(t_{1}, t_{2} \cdots t_{N}\right)=\left(\prod_{n=1}^{N} \sqrt{\sum_{j=1}^{5}\left(1-U_{n, j}\right)^{2}}\right)^{\frac{1}{N}} .
$$

In eqs. (5)-(8), $U_{j i}\left(e_{j i}\right)$ represents the degree of order of the $i$ order parameter of the attributes of the $j$ dimensions; $e_{j i}$ represents the value of the $i$ order parameter of the attributes of the $j$ dimension; $a_{j i}, b_{j i}$ refer to the maximum threshold and minimum threshold of $e_{j i}$ respectively; $c$ is the ideal value within the range of $e_{j i}, c \in\left[a_{j i}, b_{j i}\right] ; U_{j}$ represents the degree of order of each dimensional attribute; $\alpha_{j}$, $\beta_{j}$ repre-

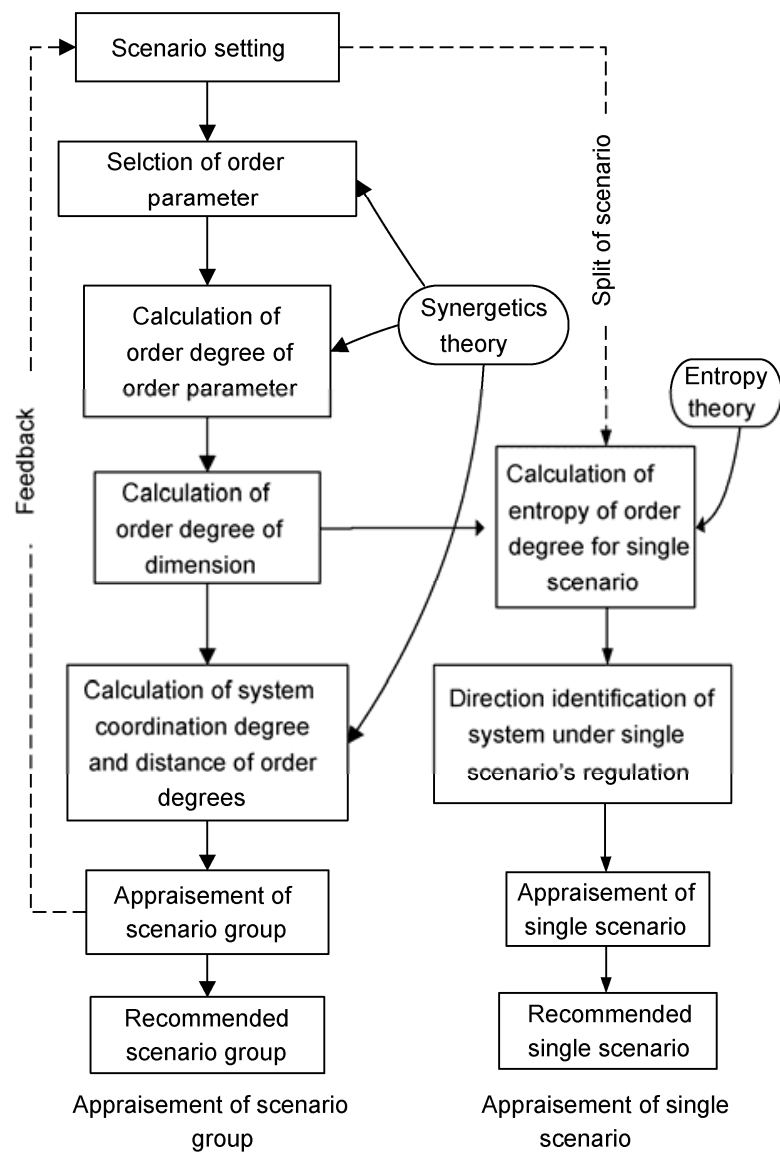

Figure 3 Multi-dimensional regulatory scheme evaluation processes for the river basin.

sent the relevant proportion of the $i$ order parameter $e_{j i}$ of the attributes of the $j$ dimension; $S_{y}$ represents the degree of order based on entropy of the water cycle system; $H(t)$ represents the degree of coordination; $U_{n, j}$ represents the degree of order of the attributes of the $j$ dimension of the water cycle system within the $n$ regulation time period, in which $N$ is the total regulation time period.

\subsection{Material and data preparation}

The Haihe River Basin is an economically and socially developed area that serves as an important industrial base, high and new technology industrial base, and major grain producing area in China. In 2007, the total population was 137 million, the urbanization rate was $46.7 \%$, the GDP was 356 billion CNY, and the tertiary industry rate was 8:50:42. The GDP per capita in the basin was $26000 \mathrm{CNY}$, and the actual annual water supply was 40.3 billion $\mathrm{m}^{3}$. The water supply consisted of $64.6 \%$ groundwater, $22.0 \%$ local surface water, $10.9 \%$ water diverted from the Yellow River and $2.5 \%$ untraditional water sources, such as seawater, treated sewage, brackish, etc Towns accounted for $25.9 \%$ of the water consumption, while rural areas accounted for $74.1 \%$. 
The water ecological degradation in the plains areas of the Haihe River Basin is rather serious. Since the 1950s, the surface area of wetlands in the basin has decreased by $72 \%$. In 2005 , the water surface area of the 12 natural lake wetlands in the basin was $727.7 \mathrm{~km}^{2}$, and the aquatic plant communities, wild fish and crab populations, birds, and other biomass had decreased sharply. Over the same period, the amount of water flowing to the sea continually declined, and the balance between the water and sand and between the water and salt at the estuaries was severely affected.

Along with the sudden development of the Bohai Ring Economic Zone (especially for the Beijing, Tianjin and Hebei Metropolis Circle), the coastal area of the Haihe River Basin will become the center of economic development. As such, this region will undergo rapid industrial growth and become a manufacturing base. High and new technology industries will develop rapidly, which will drive the upgrading and reconstruction of traditional industries, as well as the construction of high speed railways and aviation facilities. The plains areas of the Haihe River Basin will still be the major grain producing area of China and will assume a large amount of production tasks, with self-sufficiency of the Haihe River Basin as the general objective.

This study set up basic schemes according to the comprehensive planning results for the Haihe River Basin approved by the State Council in 2010. The basic scheme adopted the hydrological series years from 1956 to 2000 and reserved a certain degree of safety in terms of water demand forecasting and water-saving, unconventional water source utilization, etc. Although the selection of hydrological series and external water diversion allocation conformed to relevant norms and regulations, the recent water resource situation in the basin water was not reflected sufficiently, and partial allocation was not reasonable. Considering the need to enhance the degree of water resource safety, it became necessary to pay greater attention to the impact of the recent relatively dry hydrological series on economic and social development in the region; therefore, this study adopted the hydrological series from 1956 to 2000 and from 1980 to 2005 (hereinafter referred to as the long series and short series, respectively). The average annual precipitation of the long series was about 11.84 billion $\mathrm{m}^{3}$ greater than that of the short series. These data were used to parallelly analyze and calculate the water demands for the current situation and national economy in 2020 and 2030 (including the water-saving level), the structural and spatial distribution of the water supply, and to analyze the regulation threshold value of the five-dimensional inclusiveness synergy for the water cycle of the Haihe River Basin.

In the five-dimensional regulation, maintenance of the water cycle stability and reproducibility and ecological system recovery were the premise for guaranteeing and supporting economic and social development. This study employed a hierarchy and progressive mode to set up the regulation circumstance schemes. The first layer was associated with the reproducibility maintenance for the water cycle system, including the dimensions of resource and ecology. The boundary circumstance parameters include precipitation, groundwater over-exploitation, the amount of water flowing to the sea, south-to-north water diversion amount, water diverted from the Yellow River, consumable water amount, and ET regulation objectives (Table 1). The second layer focused on the economic and social development and ecological environment protection synergy mode, including the economic scale, industrial structure, grain security and environmental conditions closely related to this security, and involved the dimensions of economy, society, and the environment. The boundary circumstance parameters included the GDP, tertiary proportion, grain production, urbanization rate, gross COD and amount of water flowing to the river, urban environmental water consumption and ecological water consumption (Table 2). The third layer focused on improving the water resource guarantee ability, including unconventional water resource utilization, highly-efficient use of conventional water resources (strengthening water-saving), and other regulation measures. This layer involved the dimensions of resource and economy, with the boundary circumstance parameters including renewable water consumption, brackish water consumption, rain water consumption, sea water desalination, sea water direct utilization, and the highly-efficient use of conventional water resources (Table 3 ).

The organic combination of the three layers was constructed using the combined (target years of 2007-20202030) schemes for multi-dimensional regulation series for the water cycle of the Haihe River Basin. Altogether there were 336 sets, including 96 sets (F1-F96) of combined schemes for the 1956-2000 hydrological series (long series) and 240 sets (F97-F336) of combined schemes for the 1980-2005 hydrological series (short series). In addition, 88 sets of effective schemes were screened through rational analysis, effective analysis of the degrees of order and critical thresholds, and discrimination of the comprehensive distance of the degree of coordination (including 40 sets for the long series and 48 sets for the short series).

\section{Results and discussion}

\subsection{Regulation objectives (ideal points) and scope}

To meet the national demands faced by the Haihe River Basin, basic positioning, water conservancy guarantee objectives and tasks associated with the future economic development of the Haihe River Basin were analyzed. Ten coordination indexes were then selected to represent the five-dimensional overall regulation to meet the ideal objectives (ideal points) and feasible regulation scope set up by the national demands and developmental demands of the river basin (Table 4$)$.

(i) Resource. The amount of groundwater over-exploita- 
Table 1 Layer 1: Boundary circumstance combination of reproducibility maintenance for the water cycle system (units: 0.1 billion $\mathrm{m}^{3}$ )

\begin{tabular}{|c|c|c|c|c|c|c|c|c|c|c|}
\hline \multirow{2}{*}{$\begin{array}{l}\text { Hydrologic } \\
\text { time series }\end{array}$} & \multirow{2}{*}{$\begin{array}{l}\text { Level } \\
\text { year }\end{array}$} & \multirow{2}{*}{$\begin{array}{l}\text { Scenario } \\
\text { code }\end{array}$} & \multirow{2}{*}{ Rainfall } & \multirow{2}{*}{$\begin{array}{l}\text { Groundwater } \\
\text { over-pumping }\end{array}$} & \multirow{2}{*}{$\begin{array}{c}\text { Outflow } \\
\text { to sea }\end{array}$} & \multicolumn{2}{|c|}{ SNWTP } & \multirow{2}{*}{$\begin{array}{c}\text { YR } \\
\text { diversion }\end{array}$} & \multirow{2}{*}{$\begin{array}{l}\text { Acceptable } \\
\text { water } \\
\text { consumption }\end{array}$} & \multirow{2}{*}{$\begin{array}{l}\text { Object of ET } \\
\text { control }\end{array}$} \\
\hline & & & & & & MR & ER & & & \\
\hline 2007 & 2007 reality & & 1558.5 & 81 & 17 & 0 & 0 & 43.80 & 1585.3 & 1666.3 \\
\hline \multirow{6}{*}{ 1956-2000 } & Baseline & RL07-1 & 1712.4 & 55 & 55 & 0 & 0 & 43.73 & 1701.1 & 1756.1 \\
\hline & \multirow{2}{*}{2020} & RL20-1 & \multirow{2}{*}{1712.4} & 36 & \multirow{2}{*}{64} & \multirow{2}{*}{62.42} & \multirow{2}{*}{16.8} & \multirow{2}{*}{51.20} & 1778.8 & 1814.8 \\
\hline & & RL20-2 & & 16 & & & & & 1778.8 & 1794.8 \\
\hline & \multirow{3}{*}{2030} & RL30-1 & & 0 & 68 & 2620 & 313 & \multirow{3}{*}{51.20} & 1813.1 & 1813.1 \\
\hline & & RL30-2 & 1712.4 & 0 & 93 & 86.21 & 31.3 & & 1788.1 & 1788.1 \\
\hline & & RL30-3 & & 0 & 68 & 62.42 & 16.8 & & 1774.8 & 1774.8 \\
\hline \multirow{10}{*}{ 1980-2005 } & Baseline & RS07-1 & 1594.0 & 55 & 55 & 0 & 0 & 43.73 & 1582.7 & 1637.7 \\
\hline & \multirow{4}{*}{2020} & RS20-1 & \multirow{4}{*}{1594.0} & 36 & 64 & \multirow{4}{*}{62.42} & \multirow{4}{*}{16.8} & \multirow{4}{*}{51.20} & 1660.4 & 1696.4 \\
\hline & & RS20-2 & & 55 & 55 & & & & 1669.4 & 1724.4 \\
\hline & & RS20-3 & & 45 & 35 & & & & 1689.4 & 1734.4 \\
\hline & & RS20-4 & & 26 & 68 & & & & 1656.4 & 1682.4 \\
\hline & \multirow{5}{*}{2030} & RS30-1 & \multirow{5}{*}{1594.0} & \multirow[t]{5}{*}{0} & 68 & \multirow{2}{*}{86.21} & \multirow{2}{*}{31.3} & \multirow{4}{*}{51.20} & 1694.7 & 1694.7 \\
\hline & & RS30-2 & & & & & & & 1707.7 & 1743.7 \\
\hline & & RS30-3 & & & 55 & 62.42 & \multirow{3}{*}{16.8} & & 1669.4 & 1705.4 \\
\hline & & RS30-4 & & & 50 & \multirow{2}{*}{75.0} & & & 1682.0 & 1718.0 \\
\hline & & RS30-5 & & & & & & 63.10 & 1693.9 & 1729.9 \\
\hline
\end{tabular}

a) SNWTP: South-to-North Water Transfer Project; MR: Middle Route of the SNWTP; ER: East Route of the SNWTP; YR: Yellow River.

Table 2 Layer 2: Circumstance combination of synergetic modes for economic and social development and ecological and environmental protection

\begin{tabular}{|c|c|c|c|c|c|c|c|c|c|c|c|c|c|}
\hline \multirow{3}{*}{$\begin{array}{c}\text { Level } \\
\text { year }\end{array}$} & \multirow{3}{*}{ Scenario } & \multicolumn{4}{|c|}{ Economy } & \multicolumn{3}{|c|}{ Society } & \multicolumn{2}{|c|}{ Environment } & \multicolumn{2}{|c|}{ Ecology } & \multirow{3}{*}{ Remark } \\
\hline & & \multirow{2}{*}{$\begin{array}{c}\text { GDP } \\
\left(10^{8}\right. \\
\mathrm{CNY})\end{array}$} & \multicolumn{3}{|c|}{$\begin{array}{l}\text { Industrial } \\
\text { structure }\end{array}$} & \multicolumn{2}{|c|}{ Food production } & \multirow{2}{*}{$\begin{array}{c}\text { Urbanization } \\
(\%)\end{array}$} & \multirow{2}{*}{$\begin{array}{l}\text { Volume of } \\
\text { sewage to } \\
\text { rivers }\end{array}$} & \multirow{2}{*}{$\begin{array}{l}\text { COD to } \\
\text { rivers } \\
\left(10^{4} t\right)\end{array}$} & \multirow{2}{*}{$\begin{array}{l}\text { Water for } \\
\text { environment } \\
\quad\left(10^{4} \mathrm{~m}^{3}\right)\end{array}$} & \multirow{2}{*}{$\begin{array}{l}\text { Ecology } \\
\left(10^{4} \mathrm{~m}^{3}\right)\end{array}$} & \\
\hline & & & 1 st & 2nd & $3 \mathrm{rd}$ & $\left(10^{4} \mathrm{t}\right)$ & (kg/cap.) & & & & & & \\
\hline 2007 & & 3.56 & 8 & 50 & 42 & 5320 & 389 & 47.6 & 45.2 & 105.4 & 6.34 & 0 & Food self-sufficient \\
\hline Baseline & D07-1 & 3.56 & 8 & 50 & 42 & 5320 & & 47.6 & 45.2 & 105.4 & 6.34 & 0 & Basic scenario \\
\hline \multirow[b]{2}{*}{2020} & D20-1 & \multirow[b]{2}{*}{9.01} & \multirow[b]{2}{*}{5} & \multirow[b]{2}{*}{47} & \multirow[b]{2}{*}{48} & 5400 & 357 & \multirow[b]{2}{*}{58.6} & \multirow[b]{2}{*}{54.9} & \multirow[b]{2}{*}{53.1} & \multirow[b]{2}{*}{10.09} & \multirow[b]{2}{*}{9.4} & Basic scenario \\
\hline & D20-2 & & & & & 5650 & 375 & & & & & & $\begin{array}{l}\text { Scenario for } \\
\text { comparison, } 95 \% \\
\text { food self-sufficient }\end{array}$ \\
\hline \multirow{2}{*}{2030} & D30-1 & \multirow[b]{2}{*}{16.95} & \multirow[b]{2}{*}{3} & \multirow[b]{2}{*}{45} & \multirow[b]{2}{*}{52} & 5500 & 350 & \multirow[b]{2}{*}{66.4} & \multirow[b]{2}{*}{61.4} & \multirow[b]{2}{*}{30.7} & \multirow[b]{2}{*}{12.65} & \multirow[b]{2}{*}{14.2} & Basic scenario \\
\hline & D30-2 & & & & & 5900 & 375 & & & & & & $\begin{array}{l}\text { Scenario for com- } \\
\text { parison }\end{array}$ \\
\hline
\end{tabular}

Table 3 Layer 3: Circumstance combination for improving the ability to guarantee water resources

\begin{tabular}{|c|c|c|c|c|c|c|c|c|c|}
\hline \multirow[b]{2}{*}{$\begin{array}{l}\text { Level } \\
\text { year }\end{array}$} & \multirow[b]{2}{*}{ Scenario } & \multicolumn{6}{|c|}{ Exploitation of irregular water resources $\left(10^{4} \mathrm{~m}^{3}\right)$} & \multirow[b]{2}{*}{$\begin{array}{l}\text { Water demand } \\
\qquad\left(10^{4} \mathrm{~m}^{3}\right)\end{array}$} & \multirow[b]{2}{*}{ Remark } \\
\hline & & $\begin{array}{l}\text { Reclaimed } \\
\text { water }\end{array}$ & Brackish & Rain & $\begin{array}{c}\text { Desalinated } \\
\text { seawater }\end{array}$ & $\begin{array}{c}\text { Seawater } \\
\text { direct used }\end{array}$ & Total & & \\
\hline 2007 & & 7.05 & 2.69 & 0.57 & 0.03 & 0.0 & 10.34 & & \\
\hline Baseline & E07-1 & 7.05 & 2.69 & 0.57 & 0.03 & & 10.34 & & Basic scenario \\
\hline \multirow{2}{*}{2020} & E20-1 & 23.85 & \multirow{2}{*}{7.86} & \multirow{2}{*}{0} & 3.42 & & 35.13 & 494.66 & Basic scenario \\
\hline & E20-2 & 36.85 & & & 6.39 & 146.0 & 51.10 & 463.57 & Comparison scenario \\
\hline \multirow{2}{*}{2030} & E30-1 & 28.60 & \multirow{2}{*}{8.59} & \multirow{2}{*}{0} & 3.93 & & 41.12 & 514.78 & Basic scenario \\
\hline & E30-2 & 51.11 & & & 6.81 & 149.0 & 66.51 & 483.53 & Comparison scenario \\
\hline
\end{tabular}


Table 4 Ideal points and regulation scope for multi-dimensional critical regulation key indexes for the Haihe River Basin

\begin{tabular}{|c|c|c|c|c|c|c|c|c|}
\hline \multirow{3}{*}{ Dimension } & \multirow{3}{*}{ Key indices } & \multirow{3}{*}{$\begin{array}{l}\text { Baseline } \\
(2007)\end{array}$} & \multicolumn{2}{|c|}{ Ideal point of 2030} & \multicolumn{4}{|c|}{ Regulable range } \\
\hline & & & \multirow{2}{*}{ Value } & \multirow{2}{*}{ Weights } & \multicolumn{2}{|c|}{ Long-term } & \multicolumn{2}{|c|}{ Short-term } \\
\hline & & & & & Bottom & Upper & Bottom & Upper \\
\hline \multirow[t]{2}{*}{ Resources } & Groundwater over pumping $\left(10^{8} \mathrm{~m}^{3}\right)$ & 81 & 0 & 0.6 & 36 & 0 & 36 & 0 \\
\hline & Rate of surface water exploited (\%) & 67 & 50 & 0.4 & 45 & 67 & 50 & 67 \\
\hline Economy & GDP per capita $\left(10^{4} \mathrm{CNY}\right)$ & 2.60 & 10.76 & 0.4 & 6.0 & 10.76 & 6.0 & 10.76 \\
\hline \multirow[t]{2}{*}{ Society } & Food production per capita (kg) & 389 & 375 & 0.7 & 350 & 375 & 350 & 375 \\
\hline & $\begin{array}{l}\text { Rate of rural-urban water consumption per } \\
\text { capita (Rural/urban) }\end{array}$ & 0.70 & 0.78 & 0.3 & 0.60 & 0.80 & 0.60 & 0.80 \\
\hline \multirow[t]{2}{*}{ Ecology } & Outflow to sea $\left(10^{8} \mathrm{~m}^{3}\right)$ & 27 & 75 & 0.4 & 55 & 75 & 35 & 65 \\
\hline & Instream ecological water use $\left(10^{8} \mathrm{~m}^{3}\right)$ & & 55 & 0.6 & 28 & 55 & 28 & 65 \\
\hline Environment & COD to rivers $\left(10^{4} \mathrm{t}\right)$ & 100 & 30 & 0.5 & 60 & 30 & 60 & 30 \\
\hline
\end{tabular}

tion and the surface water development and utilization rates were used as characterization indexes to reflect the reproducibility of the water cycle of the river basin. In the Haihe River Basin, where groundwater over-exploitation is severe, the importance of indexes was reflected by the fact that the amount of groundwater over-exploitation was higher than the surface water development and utilization rate, with a ratio of $0.6: 0.4$.

Groundwater over-exploitation amount. According to the evaluation of the water resources in the Haihe River Basin, the amount of exploitable groundwater in the plains areas

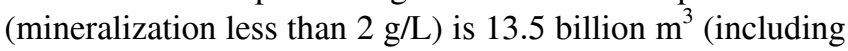
the recharge produced by the Yellow River), and the existing groundwater over-exploitation amount is about 8.1 billion $\mathrm{m}^{3}$. After the effects of the south-to-north water diversion are realized and effective measures to increase water-saving and water resource allocation are implemented, groundwater over-exploitation in the plains areas of Haihe River Basin will decrease annually. Specifically, groundwater exploitation will have decreased to 3.6 billion $\mathrm{m}^{3}$ by 2020, and in 2030 a balance between exploitation and recharge will be realized. Therefore, this study assumed zero groundwater over-exploitation as the regulation target for 2030 , with a regulation scope for groundwater over-exploitation of 0-3.6 billion $\mathrm{m}^{3}$.

Surface water development and utilization rate. The average amount of surface water in the Haihe River Basin from 1995 to 2007 was 14.8 billion $\mathrm{m}^{3}$, with an annual average water supply of 9.9 billion $\mathrm{m}^{3}$ and a surface water development and utilization degree of $67 \%$, which exceeded the upper limit value $(40 \%)$ of the internationally recognized surface water resource development and utilization rate. Currently, the amount of mountainous river runoff is continuing to decrease, the rivers in the plains areas are becoming dry, the wetlands are withering, and the amount of water flowing into the sea is decreasing sharply. The model simulation showed that after the south-to-north water diver- sion project, the surface water development and utilization rate of the Haihe River Basin in 2020 and 2030 can be reduced to $60 \%$ and $59 \%$, respectively. Therefore, this study set a target surface water development and use rate of $50 \%$. The regulation range under the long series hydrological conditions of relative abundance is $45 \%-67 \%$, while that of the short series is $50 \%-67 \%$.

(ii) Economy. The water consumption for the GDP per capita and GDP per ten thousand CNY are used to reflect the characterization indexes representing the scale of economic development and water resource utilization efficiency. In the Haihe River Basin, which is currently undergoing a severe water resource shortage, the water consumption index for the GDP per ten thousand CNY is more important. The proportion of these two values is 0.4:0.6.

GDP per capita. According to the three step developmental strategy for the first 50 years of the 21 st century proposed by the 15th Party Congress (of the Chinese Communist Party), the Haihe River Basin is anticipated to be well-off in 2020, and achieve basic modernization in 2030, with the GDP per capita in 2020 and 2030 reaching 52000 CNY and RMB 100000 CNY, respectively. In addition, the summary of forecasting results by the provincial development and reform departments in the Haihe River Basin indicate that the GDP for the Haihe River Basin will increase from 3560 billion CNY in 2007 to 9120 billion CNY in 2020, while the GDP per capita will reach $60000 \mathrm{CNY}$, with an annual average growth rate of about $7.5 \%$. If the average annual growth rate of the GDP for 2020-2030 decreases by $1 \%$ from 2007 to 2020 , the GDP per capita in 2030 will reach RMB $107600 \mathrm{CNY}$. Therefore, this study assumed a GDP per capita of $107600 \mathrm{CNY}$ as the target for economic growth in 2030, with a regulation scope in 2020 of 40000$70000 \mathrm{CNY} /$ person and 60000-107600 CNY/person in 2030.

Comprehensive water consumption for GDP per ten thousand CNY. This factor reflects the amount of water 
saved and water use efficiency, as well as the level of water for economic development. A higher comprehensive water consumption for GDP per ten thousand CNY is associated with a smaller scale of supportable economic development. Therefore, reducing the comprehensive water consumption for GDP per ten thousand CNY by improving the water use efficiency and benefit is an important way of guaranteeing and supporting the economic and social development of the Haihe River Basin. According to the revised and compiled accomplishments of the comprehensive planning for the Haihe River Basin, in 2030, the GDP per capita will reach $107600 \mathrm{CNY}$ and the comprehensive water consumption for GDP per ten thousand CNY will have decreased from 113 $\mathrm{m}^{3}$ in 2007 to $54 \mathrm{~m}^{3}$ in 2020 and $30 \mathrm{~m}^{3}$ in 2030 . Therefore, in this study a comprehensive water consumption for GDP per ten thousand CNY of $30 \mathrm{~m}^{3}$ was taken as the target for 2030 , with a regulation range in 2020 of $50-75 \mathrm{~m}^{3} / \mathrm{ten}$ thousand CNY and 30-55 $\mathrm{m}^{3} /$ ten thousand CNY in 2030 .

(iii) Society. The grain output per capita and ratio of the domestic water use per capita of urban area to rural area. were used to reflect the scale of grain production and differences between urban and rural domestic water consumption to ensure the basic water consumption for public welfare industries and vulnerable groups. The ratio is $0.7: 0.3$.

Grain output per capita. The Haihe River Basin is a major grain producing area in China and the total grain output in 2007 was 53.2 million tons, accounting for $10.6 \%$ of the national grain output. The occupancy of the basin per capita is $389 \mathrm{~kg}$, indicating food security for the Haihe River Basin. With the economic expansion and population increase in Beijing, Tianjin, the Hebei Metropolis Circle and the Bohai Ring Economic Zone, the grain consumption demands will increase rigidly, while the restraints on grain output as a result of decreasing cultivated lands, water shortage, and climate change have become increasingly prominent, and it needs food import in the future, but the proportion to national grain output will remain at the same level as that of 2007. According to a target national grain consumption per capita in 2020 of not less than $395 \mathrm{~kg}$ proposed in the Medium and Long Term (2008-2020) Program Planning for National Grail Yield, if 95\% is taken as the degree of self-sufficiency, the occupancy per capita will reach $375 \mathrm{~kg}$; therefore, a grain output per capita of $375 \mathrm{~kg}$ was assumed as the ideal grain output in the Haihe River Basin. If $10 \%$ of the proportion of the national grain output by the Haihe River Basin remains unchanged, then the national grain output should reach 54 million tons in 2020, and the grain occupancy per capita shall be $357 \mathrm{~kg}$. In addition, the national grain output should reach 55 million tons in 2030, and the grain occupancy per capita should be about $350 \mathrm{~kg}$. Accordingly, the regulation range for grain output per capita in the Haihe River Basin was 350-375 kg.

Ratio between urban and rural domestic water consumptions per capita. The urban water consumption quota for the Haihe River Basin in 2007 was $95 \mathrm{~L} /$ (person d), and that for the rural area was $66 \mathrm{~L} /($ person d), with a ratio between urban and rural domestic water consumption per capita of (rural/urban) 0.70. From the ideal perspective, the rural domestic water consumption quota in 2020 and 2030 should gradually approach the current level of city. If $98 \mathrm{~L} /($ person d) for the rural domestic water consumption quota for Beijing in 2007 is taken as the rural domestic water consumption quota for the Haihe River Basin in 2030, then the ratio between urban and rural domestic water consumption per capita is 0.78 .

(iv) Ecology. The amount of water flowing to the sea and insream ecological water consumption reflecting the ecological water consumption conditions were used as the characterization indexes to weigh the ecological environment to ensure the basic water consumption for the ecological environment. The proportion of water flowing to the sea and insream ecological water demand was 0.6:0.4.

Amount of water flowing to the sea. The average annual amount of water flowing to the sea for the Haihe River Basin from 1956 to 2005 was about 9.3 billion $\mathrm{m}^{3}$, accounting for approximately $43 \%$ of the average annual natural river runoff amount of 21.6 billion $\mathrm{m}^{3}$ over the same period. The average annual amount of water flowing to the sea for the Haihe River Basin from 1980 to 2005 was about 3.5 billion $\mathrm{m}^{3}$, so that it makes the estuarine ecosystem worse. According to the results of related studies, the average annual amount of water flowing to the sea needed to maintain the dynamic balance of the main estuary sediments for the Haihe River Basin was 7.5 billion $\mathrm{m}^{3}$, and the appropriate amount was 12.1 billion $\mathrm{m}^{3}$. Additionally, the average annual amount of water flowing to the sea required to maintain the salinity balance of the aquatic organisms (fishes) in the main estuaries of the Haihe River Basin was 1.8 billion $\mathrm{m}^{3}$, and the appropriate amount was 5 billion $\mathrm{m}^{3}$. After comprehensively weighing the water demands of the national economy and ecological environment, the appropriate amount required to maintain the dynamic balance of estuarine sediment was considered to be too large, while the minimum amount of water flowing to the sea needed to maintain the balance of salinity for aquatic organisms (fishes) in the main estuaries was considered to be too small; therefore, the appropriate range of water flowing to the sea was set to 5.0-7.5 billion $\mathrm{m}^{3}$. Under the conditions of the 1980-2005 hydrological series, one third of the natural river runoff amount was about 5.5 billion $\mathrm{m}^{3}$; however, in the Haihe River Basin during severe water shortage it is very difficult to guarantee one third of the natural river runoff. Therefore, 5.5 billion $\mathrm{m}^{3}$ was assumed as the ideal amount of water flowing to the sea based on the short series, while 7.5 billion $\mathrm{m}^{3}$ was assumed as the ideal amount of water flowing to the sea for long series.

Instream ecological water consumption. The Tennant method was used to analyze the amount of instream ecological water, $15 \%-30 \%$ of average natural river runoff in mountainous area and $5 \%-15 \%$ in plain area. Analysis re- 
vealed that the amount of instream ecological water for the Haihe River Basin was 4.94 billion $\mathrm{m}^{3}$, among which the planned amount of ecological water for the 15 rivers in mountainous areas was 1.1 billion $\mathrm{m}^{3}$, while for the 24 rivers in the plains areas it was 2.81 billion $\mathrm{m}^{3}$, and for the 13 planned wetlands it was 1.03 billion $\mathrm{m}^{3}$. If the ecological water was allocated based on a reliability of $95 \%$, there would be no need to allocate water for the 15 planned rivers in the mountainous areas, 737 million $\mathrm{m}^{3}$ of water will be allocated for the 11 planned rivers in the plains areas, and 9 of 13 wetlands (excluding Beida Port, Hengshui Lake, Daliangdian, and En'xianwa, which will receive water from the south-to-north water transfer project) will receive 681 million $\mathrm{m}^{3}$ of water. Overall, the total amount of water allocated for rivers in plain areas and wetlands in the Haihe River Basin would be 943 million $\mathrm{m}^{3}$ in 2020 and 1.418 billion $\mathrm{m}^{3}$ in 2030 .

(v) Environment. The COD of sewage discharged to the river and qualification range in water function areas reflecting the major pollution load discharge status were used as the characterization indexes for weighing the environmental conditions. The two indexes were equally important, with a ratio of $0.5: 0.5$.

COD of sewage discharged to the river. A major factor affecting the water environment threshold is the designed flow. A material series that is too short cannot reflect the hydrological rules, while one that is too long cannot reflect the influence of human activities, especially that of the low water flow drought period. Internationally, the 7Q10 method is usually used to calculate the designed flow. In this method, the average flow on the seven driest days under a reliability of $90 \%$ and a natural state is taken as the minimum designed flow. As this standard is relatively high, in China it is stipulated that the average flow in the driest month in the last ten years or the average flow in the driest month under a reliability of $90 \%$ shall be used as the designed flow for regular rivers (Technical Principles and Methods for Formulating Local Water Pollution Emission Standards, GB3839-83, 2006). Based on the water resource conditions of the Haihe River Basin, the average flow during drought months under a reliability of $75 \%$ or an average flow during the drought period in typical years shall be selected as the designed flow. This value accounts for about $15 \%$ of annual average runoff which is slightly higher than the minimum ecological water demand calculated by the Tennant method.

There were 1177 sewage drain outlets in the Haihe River Basin that were actually measured in 2007. During this year, the actual amount of sewage flowing to the river was 4.52 billion tons and the COD of water flowing into the river was 1.051 million tons. The calculated results showed that the pollutant loading ability of COD and $\mathrm{NH}_{3}-\mathrm{N}$ were 292700 t/a and $13900 \mathrm{t} / \mathrm{a}$, respectively, causing 70\% of the water function areas to exceed the standard. However, based on the calculations of the present study, only $28 \%$ of the rivers exceeded the standard in 1980, and the corresponding pollutant discharge was about 400000 tons. This value exceeded the pollutant carrying capacity by about $33 \%$. Therefore, this study assumed a sewage discharge COD of about 300000 tons as the target for 2030, with a regulation range for 2020 of 500000-800000 tons and 300000-500000 tons for 2030.

Qualification rate in water function areas. The Haihe River Basin is divided into 524 water function areas. In 2007, the water quality in 146 areas was qualified, and the qualification rate was only $28 \%$. The COD pollutant carrying capacity of water function areas was calculated according to the water quality objectives of the water functions and designed hydrological conditions, and the inflow sewage amount in target years was predicted based on the forecasted water demand and degree of sewage treatment. In 2020 , the planned qualification rate for water function areas was $63 \%$, with a corresponding COD inflow control amount of 530000 tons and an inflow sewage amount of 5.5 billion $\mathrm{m}^{3}$. In 2030, the planned qualification rate for water function areas was $100 \%$, with a corresponding COD inflow control amount of 310000 tons and an inflow sewage amount of 6.1 billion $\mathrm{m}^{3}$. Therefore, a planned qualification rate for water function areas of $100 \%$ was set as the regulation objective for 2030 .

\subsection{Regulatory modes and threshold value analysis}

To effectively identify the impact of water consumption of one dimension on several other dimensions, the dimensions were classified into different levels at the ideal point of the characterization indexes and within the regulation scope to quantitatively analyze the impact of the change from the lower limit to the upper limit of a certain dimension on other dimensions.

Among the five dimensions, the resource, ecology, and economy were closely related to the water cycle. These factors can be expressed as the amount of groundwater over-exploitation and the amount of water flowing to the sea to determine the range of water available for the national economy under the specific inter-basin water diversion scale; therefore, the first step for critical regulation is analysis of the impact of changes in the resource (groundwater over-exploitation) and ecology (amount of water flowing to the sea) on the economy and clarification of the reasonable range of water required to maintain the national economy in the feasible resource and ecological threshold value range. This can be done using the following equation:

$$
W=f\left(O_{w}, F s_{w}\right),
$$

where, $W$ represents the total water consumption for the national economy; $O_{w}$ represents over-exploitation amount; $F s_{w}$ represents amount of water flowing to the sea.

The second step is to analyze the relationships between the economic structure, grain security and economic devel- 
opment scale within the feasible water consumption range for the national economy. Because the amount of water consumed for grain production is significantly higher than that consumed by other industries, the key is to clarify the supportable economic development scale, coordinate the relationship between the economic development scale and grain security, and determine the grain security regulation threshold values within the reasonable water consumption range for the national economy and grain security range. This is conducted as follows:

$$
\mathrm{GDP}=g(W, F),
$$

where, $F$ represents grain output, $W$ represents the total water consumption for the national economy, $F$ represents grain output. The third step is to establish the relationships between the economic development scale, grain security and COD, discriminate the impact of economic development on the environment, and propose the COD regulation threshold value. To accomplish this, the following equation is used:

$$
\mathrm{COD}=h(\mathrm{GDP}, F) \text {, }
$$

where, COD represents COD sewage discharged to the river.

(i) Over-exploitation, amount of water flowing to the sea and water consumption for the national economy. According to ideal objective and regulation range for dimensions of resources, ecology, economy in 2030, the water is allocated among of national economy sectors with the limitation. The low limit is set with the groundwater over-exploitation amount and the available water amount for national economy when the amount of water flowing to the sea reaches 6.8 billion $\mathrm{m}^{3}$. The up limit is set with the groundwater overexploitation of 3.6 billion $\mathrm{m}^{3}$ and the available water amount for national economy when the amount of water flowing to the sea reaches 3.5 billion $\mathrm{m}^{3}$. The results showed that under the conditions of the 1980- 2005 hydrological series, the amount of water flowing to the sea increased from 3.5 billion $\mathrm{m}^{3}$ to 6.8 billion $\mathrm{m}^{3}$ and the groundwater over-exploitation was reduced from 3.6 billion $\mathrm{m}^{3}$ to zero while in 2030 , the water available for the national economy decreased from 47.5 billion $\mathrm{m}^{3}$ to 41.5 billion $\mathrm{m}^{3}$ (Figure 4). The relationships among the above three factors are expressed as follows:

$$
Z=-0.9725 \times(X-Y)+485.21
$$

where, $Z$ represents the water available for the national economy $\left(100\right.$ million $\left.\mathrm{m}^{3}\right) ; X$ represents the amount of water flowing to the sea $\left(100\right.$ million $\left.\mathrm{m}^{3}\right) ; Y$ represents the allowable groundwater exploitation (100 million $\left.\mathrm{m}^{3}\right)$.

Similarly, we can conclude that even the amount of groundwater over-exploitation was not allowed and the amount of water flowing to the sea reached 9.3 billion $\mathrm{m}^{3}$ (accounting for $43 \%$ of the average annual natural river runoff of the long series) under the conditions of the 19562000 hydrological series. In addition, the water available for

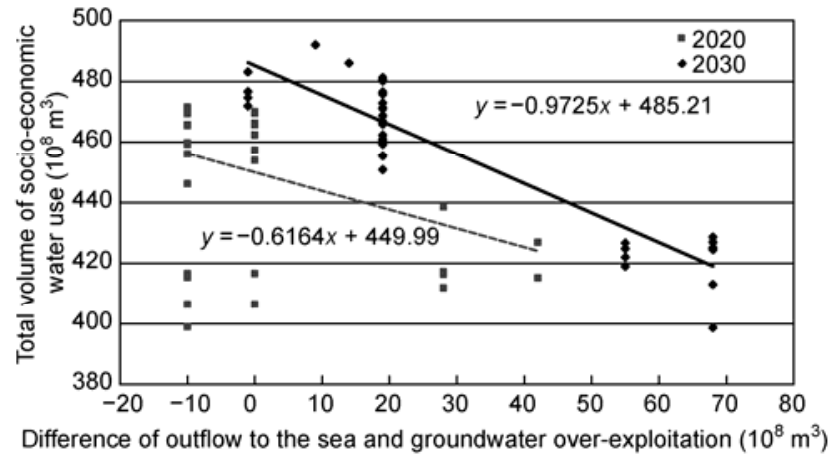

Figure 4 Relationships among the amount of water flowing to the sea, groundwater over-exploitation amount and water available for the national economy (1980-2005 series).

the national economy was above 49 billion $\mathrm{m}^{3}$.

(ii) Water available for the national economy, grain output and GDP. The total GDP is closely related to the industrial structure because the amount of water required by different industries varies greatly. Under competitive water conditions, the relationship between ensuring grain safety and guaranteeing the GDP growth is very subtle.

The analysis showed that under the conditions of the 1956-2000 hydrological series, the water available for the national economy in 2030 would be within 490-510 billion $\mathrm{m}^{3}$. Furthermore, if the grain output reached 59 million tons (375 kg per capita), the GDP will be lower than 12000 billion $\mathrm{CNY}$, which is significantly lower than the objective of 16720 billion $\mathrm{CNY}$ in the comprehensive planning for the Haihe River Basin (basic scheme). If the grain safety is reduced to the lower limit and the grain output is regulated to be within 55 million tons ( $350 \mathrm{~kg}$ per capita) and 57 million tons (365 kg per capita), the GDP can reach 16300-16560 billion CNY, which essentially realizes the objective of the basic scheme. However, under the conditions of the 1980-2005 hydrological series, if the water consumption for vegetables and other crops were reduced to $50 \%$ of the planned value and grain output controlled at 57 million tons, the GDP in 2030 would have difficulty reaching 16000 billion CNY (Figure 5).

(iii) GDP and COD of water flowing into the river. The analysis and regulation results for different combined schemes showed that the GDP and COD of water flowing into the river increase proportionally. When the GDP reached 16000 billion CNY, to ensure the quality of water functional areas the COD of water flowing into the river must be controlled within 330000 tons (Figure 6). Therefore, the COD inflow critical regulation threshold value for 2030 was set to 330000 tons.

(iv) WEDP and water consumption threshold value. The actual water consumption for the Haihe River Basin in 2007 was 38.45 billion $\mathrm{m}^{3}$, with a GDP of 3560 billion CNY. After deduction of the water resource depletion value, water ecological degradation and water environment protection value, the WEDP in 2007 was 2890 billion CNY, indicating 


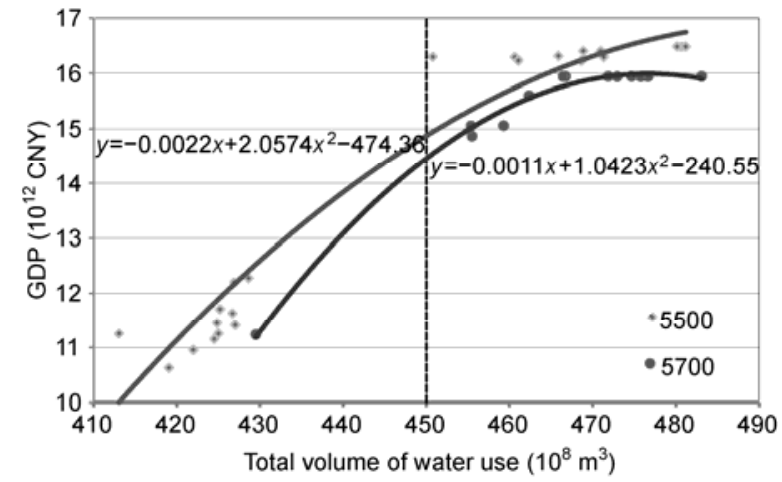

Figure 5 Relationships among the grain output in 2030, GDP and the water available for the national economy (1980-2005 series).

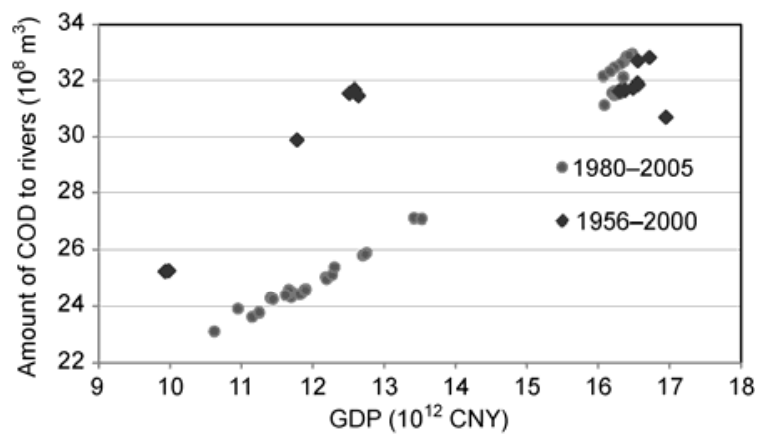

Figure 6 Relationship between GDP and COD of water flowing into the river.

that the water resource consumption and water environmental degradation in the Haihe River Basin had become severe.

After considering the water resource depletion and water ecological degradation caused by water resource development and utilization, the GDP under the maximum WEDP of the Haihe River Basin under the current conditions was 3230 billion CNY, the water resource depletion value was about 150 billion $\mathrm{CNY}$, the water ecological degradation value was about 60 billion $\mathrm{CNY}$, the water environmental protection expenditure was about 20 billion CNY, and the reasonable water consumption was about 34.3 billion $\mathrm{m}^{3}$. After deduction of the external water diversion amount and other nonconventional water resource use, the rational local water resource development and utilization threshold value for the current situation was 29 billion $\mathrm{m}^{3}$, the actual local water resource use for the current year was 33.2 billion $\mathrm{m}^{3}$, and the over-development and use threshold value was about 4 billion $\mathrm{m}^{3}$, indicating that the negative effects of water consumption greatly weakened the positive output of water consumption. The GDP under the maximum WEDP of the Haihe River Basin in 2030 is 16720 billion CNY, the corresponding water resource depletion value is about 290 billion CNY, the water ecological degradation value is about 280 billion CNY, the water environmental protection expenditure is about 200 billion CNY, and the reasonable water consumption is 47.4 billion $\mathrm{m}^{3}$. After deduction of the planned external water diversion amount and other unconventional water resources, the reasonable local water resource development and use threshold is 28 billion $\mathrm{m}^{3}$ (Figure 7).

\subsection{Five-dimensional synergetic schemes}

The limitation of water resources and competitiveness of water consumption in the Haihe River Basin make it difficult to attain ideal values for the order parameters of the five dimensions at the same time, and increasing the order of the sub-systems of a certain dimension may cause a decrease in the degree of order of the sub-systems of other dimensions. Thus, an overall balance of the five dimensions is necessary. This study adopted the SEAMUR model, applied the synergetic theory to balance the order of subsystems of the five dimensions, employed system information entropy to discriminate the evolution direction of the water cycle system, and used the degree of coordination and degree of the comprehensive distance of coordination to select relatively ideal series for the combined schemes. The ten macro characterization indexes (order parameters) of the five-dimensional coordination for the long series and short series are listed in Table 5. Based on these, 88 effective schemes for comprehensive distances for the degree of coordination for both series were proposed, and 14 combined schemes were recommended through analysis and comparison (Table 6). The results for ideal points, basic schemes, and recommended schemes for the five-dimensional competition balance are shown in Figure 8 and Figure 9. As shown in the figure, the average annual rainfall in the Haihe River Basin for short series was about 11.8 billion $\mathrm{m}^{3}$ less than that of the long series. To realize the economic development objective (GDP: 16700 billion CNY), the objectives for resources, ecology, and society must be neglected.

\section{Conclusions}

In this study, a multi-dimensional overall regulation system

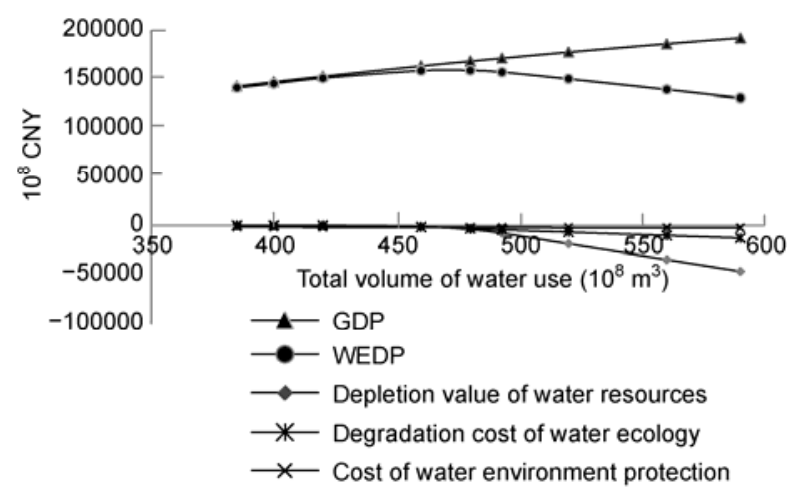

Figure 7 Relationship between water consumption and the WEDP of the Haihe River Basin in 2030. 
Table 5 Ideal point, regulable range and weights of five-dimensions

\begin{tabular}{|c|c|c|c|c|c|c|c|c|c|c|}
\hline \multirow[b]{2}{*}{ Item } & \multicolumn{2}{|c|}{ Resources } & \multicolumn{2}{|c|}{ Economy } & \multicolumn{2}{|c|}{ Society } & \multicolumn{2}{|c|}{ Environment } & \multicolumn{2}{|c|}{ Ecology } \\
\hline & $\begin{array}{l}\text { Rate of } \\
\text { surface } \\
\text { water } \\
\text { exploited } \\
(\%)\end{array}$ & $\begin{array}{c}\text { Groundwater } \\
\text { over pumping } \\
\left(10^{8} \mathrm{~m}^{3}\right)\end{array}$ & $\begin{array}{l}\text { GDP per } \\
\text { capita } \\
\left(10^{4} \mathrm{CNY}\right)\end{array}$ & $\begin{array}{c}\text { Average } \\
\text { water use } \\
\text { of } 10^{4} \mathrm{GDP} \\
\left(\mathrm{m}^{3}\right)\end{array}$ & $\begin{array}{c}\text { Rate of } \\
\text { rural-urban water } \\
\text { consumption per } \\
\text { capita } \\
\text { (Rural/urban) }\end{array}$ & $\begin{array}{l}\text { Food } \\
\text { production } \\
\text { per capita } \\
(\mathrm{kg})\end{array}$ & $\begin{array}{l}\text { Outflow } \\
\text { to sea } \\
\left(10^{8} \mathrm{~m}^{3}\right)\end{array}$ & $\begin{array}{l}\text { Instream } \\
\text { ecological } \\
\text { water } \\
\text { consumption } \\
\left(10^{8} \mathrm{~m}^{3}\right)\end{array}$ & $\begin{array}{l}\mathrm{COD} \text { to } \\
\text { rivers } \\
\left(10^{4} \mathrm{t}\right)\end{array}$ & $\begin{array}{c}\text { Instream } \\
\text { ecological } \\
\text { water use } \\
\left(10^{8} \mathrm{~m}^{3}\right)\end{array}$ \\
\hline \multicolumn{11}{|l|}{ 1956-2000 } \\
\hline Ideal point & 50 & 184 & 10.76 & 30 & 0.78 & 375 & 75 & 42.3 & 30 & $100 \%$ \\
\hline Minimal value & 45 & 184 & 6.00 & 30 & 0.60 & 350 & 55 & 35.0 & 30 & $60 \%$ \\
\hline Maximal value & 67 & 220 & 10.76 & 55 & 0.80 & 375 & 93 & 45.0 & 60 & $100 \%$ \\
\hline Weight & 0.4 & 0.6 & 0.4 & 0.6 & 0.3 & 0.7 & 0.4 & 0.6 & 0.5 & 0.5 \\
\hline \multicolumn{11}{|l|}{ 1980-2005 } \\
\hline Ideal point & 50 & 184 & 10.76 & 25 & 0.78 & 365 & 50 & 42.3 & 30 & $100 \%$ \\
\hline Minimal value & 50 & 184 & 6.00 & 25 & 0.60 & 350 & 35 & 35.0 & 30 & $60 \%$ \\
\hline Maximal value & 75 & 240 & 10.76 & 56 & 0.80 & 375 & 70 & 45.0 & 60 & $100 \%$ \\
\hline Weight & 0.4 & 0.6 & 0.4 & 0.6 & 0.3 & 0.7 & 0.4 & 0.6 & 0.5 & 0.5 \\
\hline
\end{tabular}

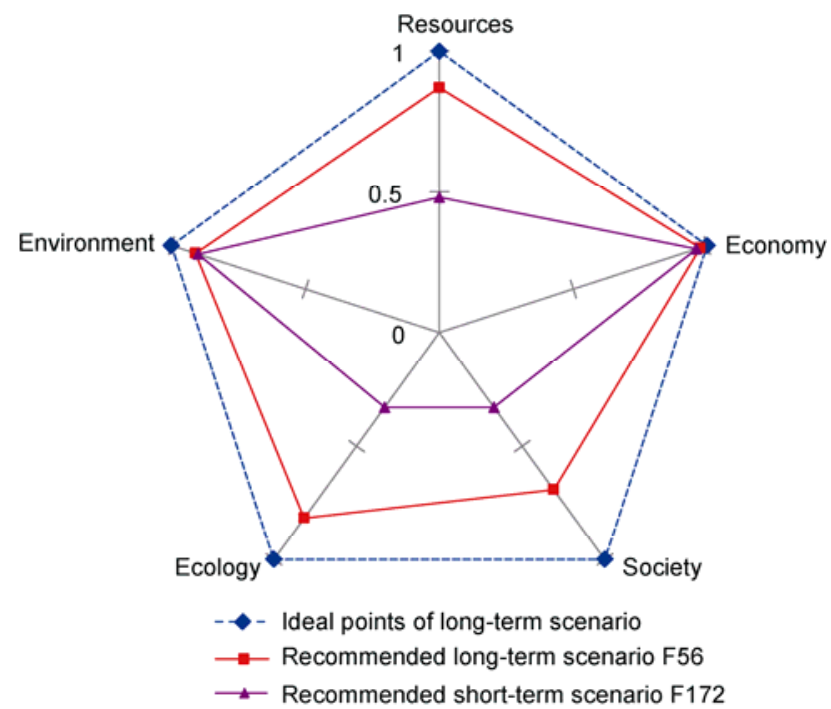

Figure 8 Radar chart for the degree of order of the five-dimensional competition and synergy in recommended schemes for long series and short series (in 2030).

based on comprehensive evaluation of multi-objective decomposition, multi-scheme hierarchical analysis and functions based on the degree of coordination is proposed to solve the failure to equally schedule the objectives of the complex water cycle system. The proposed system is able to unify the objectives of the dimensions in different forms and units into the same coordinate system for value comparison and analysis.

Usually, analysis of the relationships between the water resource and social-economy is based on single relationships. It is quite hard to handle more than three dimensional competitive issues. This study made achievements in two aspects: (1) The three-layer progressive scheme setting is presented, including mode of water cycle reproducibility maintenance ability, balance mode between socio-economic development and eco-environmental protection, improving the water resource guarantee ability. (2) The gross control indexes and regulation threshold value for five-dimensional competition balancing are proposed based on the comparison of a series of three-layer progressive schemes to improve the existing research method. The application in the Haihe River Basin verify that above methodologies improve the relation analysis among five-dimension ro realize the effective multi-objective decision-making for the complex water resources system. The decision-making platform for high-efficient utilization, macro strategic research, planning and management for river basins can be created in the future with suitable enhancement of the framework and models sets presented in this study. The main regulation conclusions obtained through the multi-scheme analysis are as follows:

(i) Under the conditions of the 1956-2000 hydrological series, there was abundant rainfall and the restriction of ET to water consumption for the national economy was limited. By strengthening the development and utilization of unconventional water sources and highly efficient utilization of conventional water sources, further regulation can be applied to decrease the groundwater over-exploitation in 2020 to 1.6 billion $\mathrm{m}^{3}$, realize the dynamic balance between exploitation and recharge in 2030, and control the amount of water flowing to the sea within 5.5-6 billion $\mathrm{m}^{3}$. The water consumption for the national economy while achieving an overall harmony of the five-dimensional competitive balance shall be controlled within 50.5 billion $\mathrm{m}^{3}$ (if phase II of the south-to-north water diversion project is implemented as scheduled) to 49 billion $\mathrm{m}^{3}$ (if phase II of the project is not implemented as scheduled). If the grain output capacity in 


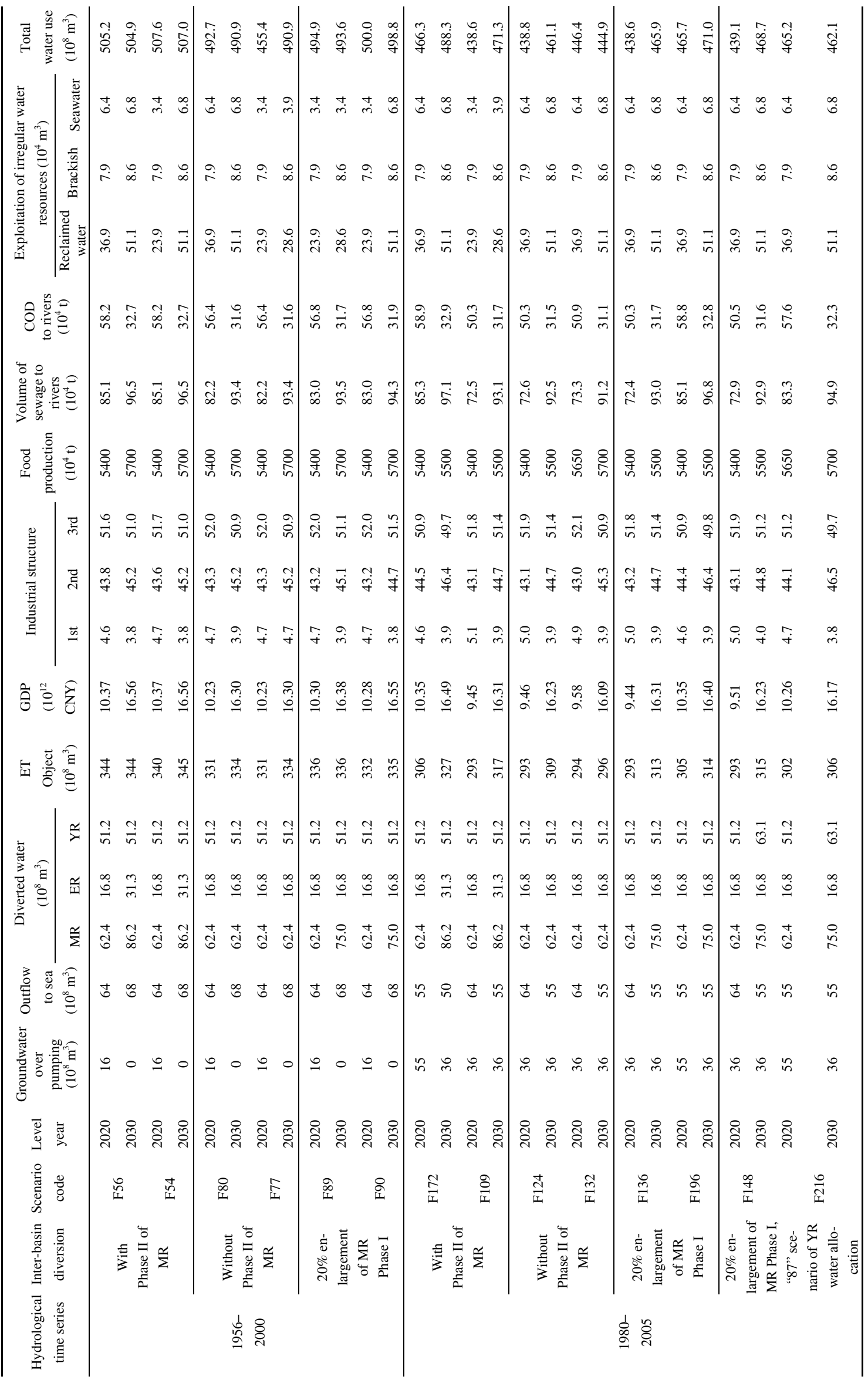



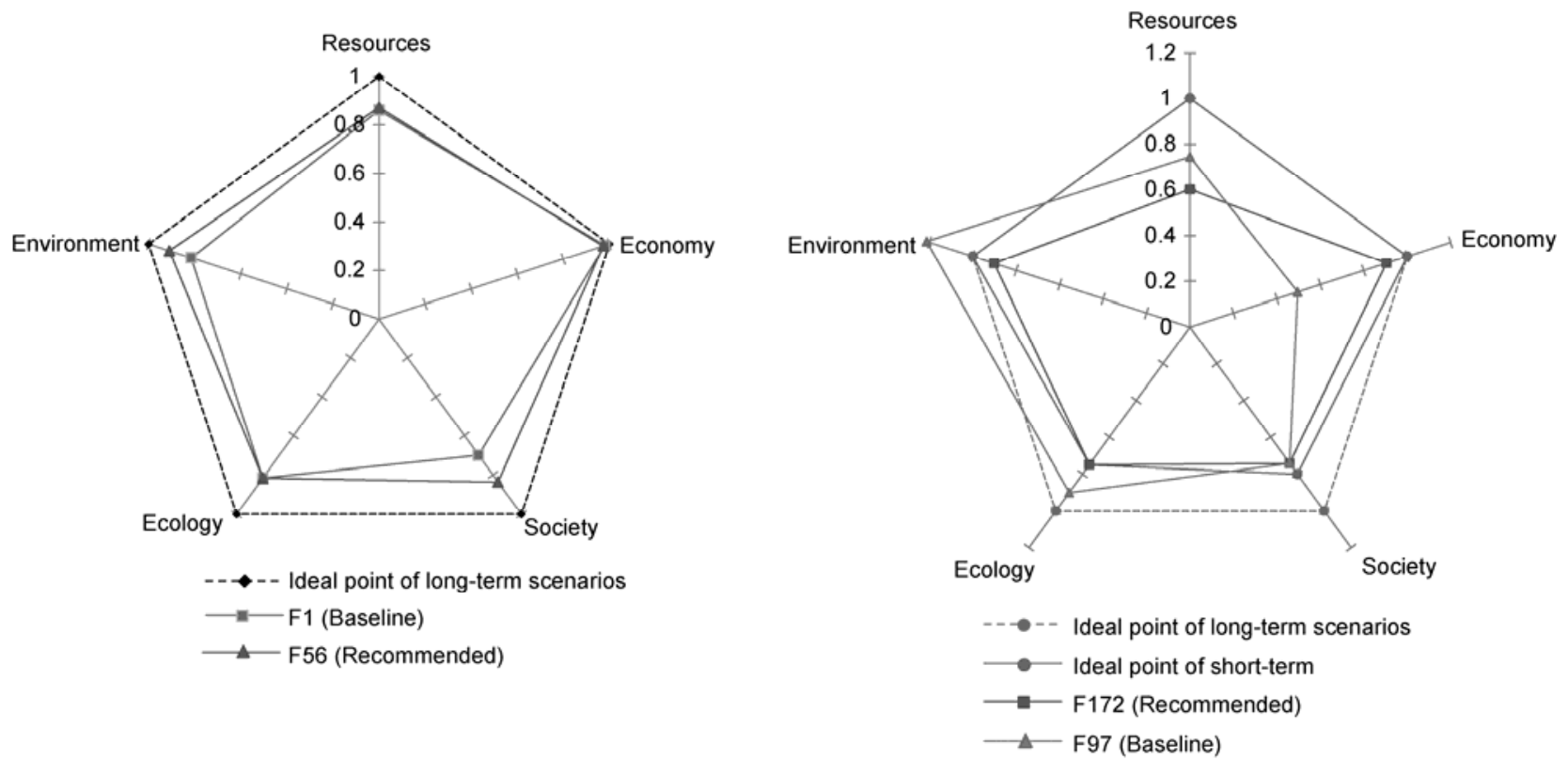

Figure 9 Radar chart for the degree of order of five-dimensional synergy (2030).

2030 is guaranteed at 57 million tons, the total GDP can reach 16300-16560 billion CNY. Additionally, the GDP when phase II of the south-to-north water diversion project is not implemented will be $1.57 \%$ lower than that when phase II of the project is implemented. For 2030, the gross control indexes are as follows: the total local surface water intake amount is $10.2-10.8$ billion $\mathrm{m}^{3}$, the groundwater exploitation amount is 18.4-20.3 billion $\mathrm{m}^{3}$ (basically realizing zero groundwater over-exploitation), the external water diversion amount is $14.2-16.7$ billion $\mathrm{m}^{3}$, the total water consumption for the national economy is $49.0-50.5$ billion $\mathrm{m}^{3}$, the total COD of sewage discharged to the river is 329000 tons, the instream ecological water is 12.9 billion $\mathrm{m}^{3}$, the amount of water flowing to the sea is 7 billion $\mathrm{m}^{3}$, and the grain output capacity is $\mathbf{5 7}$ million tons.

(ii) Under the conditions of the 1980-2005 dry hydrological series, restriction of ET to the water consumption for national economy is remarkable. If the objectives for groundwater over-exploitation (3.6 billion $\mathrm{m}^{3}$ in 2020 , balance between exploitation and recharge in 2030), amount of water flowing to the sea (6.4 billion $\mathrm{m}^{3}$ in $2020,6.8$ billion $\mathrm{m}^{3}$ in 2030) set up in the basic scheme, and phase II of the south-to-north water diversion project is implemented as scheduled and the unconventional water utilization amount is increased to 6.65 billion $\mathrm{m}^{3}$, only $67 \%$ of the objective value of the planned GDP can be realized. Therefore, the objectives of the five dimensions need to be coordinated comprehensively.

Under the conditions of the 1980-2005 hydrological series, greatly improving the utilization efficiency of the conventional water resources and enhancing the amount of water used by unconventional water resources is necessary. To accomplish this, regulations and restrictions on resources, ecology, and society must be moderately relaxed to realize overall coordination of the five dimensions. In 2030, the groundwater over-exploitation is controlled at 3.6 billion $\mathrm{m}^{3}$, the amount of water flowing to the sea is controlled at approximately 5 billion $\mathrm{m}^{3}$, the grain output capacity is kept at 55 million tons, the water consumption for the national economy is controlled at 46 billion $\mathrm{m}^{3}$ (if phase II of F124 is not implemented as scheduled, and the over-exploitation will be 3.6 billion $\mathrm{m}^{3}$ ) to 48.5 billion $\mathrm{m}^{3}$ (if phase II of F172 is implemented as scheduled, and the over-exploitation will be 3.6 billion $\mathrm{m}^{3}$ ). To maintain basic GDP growth speed, the tertiary proportion shall be adjusted from 3.9:46.4:49.7 (if phase II of F172 is not implemented as scheduled) to 3.9:44.7:51.4 (if phase II of F172 is not implemented as scheduled), and the total GDP realized will be 16230-16490 billion CNY. The analysis showed that under the conditions of the 1980-2005 hydrological series, timely implementation of phase II of the south-to-north water diversion project is necessary. The gross control indexes in 2030 are as follows: the total local surface water intake amount is 10.2-10.8 billion $\mathrm{m}^{3}$, the groundwater exploitation amount is 18.4-20.3 billion $\mathrm{m}^{3}$ (basically realizing zero groundwater over-exploitation), the external water diversion amount is $14.2-16.7$ billion $\mathrm{m}^{3}$, the total water consumption for the national economy is $49.0-50.5$ billion $\mathrm{m}^{3}$, the total COD of sewage discharged to the river is 329000 tons, the instream ecological water consumption is 12.9 billion $\mathrm{m}^{3}$, the amount of water flowing to the sea is 7 billion $\mathrm{m}^{3}$, and the grain output capacity is 57 million tons.

This work was supported by the National Natural Science Foundation of China (51021066, 50939006), the National Basic Research Program of 
China (2006CB403408), and Special Funds for Scientific Research on Public Welfare of the Ministry of Water Resources of China (201001018, 201101016).

1 Liu C M, Yu J G, Eloise K. Groundwater exploitation and its impact on the environment in the North China plain. Water Intel, 2001, 26: 265-272

2 Fu G T, David B, Soon-Thiam K. Multiple objective optimal control of integrated urban wastewater systems. Environ Model Softw, 2008, 23: $225-234$

3 Liu J H, Qin D Y, Wang H, et al. Dualistic water cycle pattern and its evolution in Haihe River basin. Chin Sci Bull, 2010, 55: 512-521

4 Qin D Y, Lv J Y, Liu J H, et al. Theories and calculation methods for regional objective ET. Chin Sci Bull, 2008, 53: 2384-2390

5 Xevi E, Khan S A. Multi-objective optimization approach to water management. J Environ Manage, 2005, 77: 269-277

6 Mariano C, Yamanaka V, Morales E, et al. Multi-objective optimization of water-using systems. Eur J Operat Res, 2007, 3: 1691-1707

7 Yapo P, Gupta H, Sorooshian S. Multi-objective global optimization for hydrologic models. J Hydrol, 1997, 204: 83-97

8 Merino G, Jones D, Clements L, et al. Fuzzy compromise programming with precedence order in the criteria. Appl Math Comput, 2003, 134: 185-205

9 Andrea C, Francesca P, Rodolfo S. Integration, participation and optimal control in water resources planning and management. Appl Math Comput, 2008, 206: 21-33

10 Babel M S, Gupta A D, Nayak D K. A model for optimal allocation of water to competing demands. Water Res Manage, 2005, 19: 693712

11 Andrew H, Ainsley A, Stefan H. A stochastic non-linear programming model for a multi-period water resource allocation with multiple objectives. Water Res Manage, 2008, 22: 1445-1460

$12 \mathrm{Lu}$ Q, Gan H, Zhang X M, et al. Concept and calculation approach of water depletion (in Chinese). J Hydra Engineer, 2010, 41: 1401-1406

13 Robert A Y. Determining the Economic Value of Water-Concept and Methods. Washington, D.C: Resources for the Future, 2004

14 Jones C V, Morris J R. Instrumental price estimates and residential water demand. Water Resour Res, 1984, 20: 197-202

15 Jiang W L. Theory of Values of Water Resources (in Chinese). Bei- jing: Science Press, 1998

16 Wang H, Ruan B Q, Shen D J. Theory and Practice of Water Price Based on Sustainable Development (in Chinese). Beijing: Science Press, 2000

17 Wang L, Gan H, Ni H Z, et al. Analysis of Economic Value of Water and Impacts of Related Policies (in Chinese). Beijing: China Water Resources and Hydropower Press, 2009

18 Costanza R, D'Arge R, De Groot R, et al. The value of the world's ecosystem services and natural capital. Nature, 2004, 387: 253-260

19 Liu J G, Ouyang Z Y, Stuart L P, et al. Ecology: Protecting China's biodiversity. Science, 2003, 300: 1240-1241

20 Wang J N, Yu F. Report of Accounting on China's Environmental Economy (in Chinese). Beijing: China Environment Press, 2009

21 Zhang G H, Chen S E, Fei Y H. Property of water resources shortage in Hai River basin and counter measure (in Chinese). J Hydra Engineer, 2003, 34: 113-118

22 Chen X G. Multi-Dimensional Critical Regulation of Water Cycle of Yellow River (in Chinese). Zhengzhou: Yellow River Press, 2007

23 Wang H, Qin D Y, Wang J H. State identification and multiple regulation of regional water resources shortage (in Chinese). Resour Sci, 2003, 25: 2-7

24 Huang Q, Chang J X. Theory and Technology of Multi-Dimensional Critical Regulation of Water Cycle System (in Chinese). Beijing: China Water Power Press, 2007

25 Gan H, Qin C H, Lu Q, et al. Study on calculation method of water resources depletion cost (in Chinese). J Hydra Engineer, 2011, 42: $40-46$

26 Gao M X, Xue J, Zhou J B. Economic Accounting of Integrated Environment-Basic Theory and Application in China (in Chinese). Beijing: Economic Science Press, 2007

27 Wu Z N, Zuo Q T, Ding D F. Assessment and optimization model of water resources control alternative for the Yellow River basin (in Chinese). Advances in Water Science, 2005, 15: 735-740

28 Gan Z G, Gan H, Wang L, et al. Tradeoff approach of multiple objective analysis in the Haihe River Basin. J Food Agri Environ, 2010, 8: 991-995

29 Gan H, Zhu Q L, You J J, et al. Alternative avaluation and selection based on order degree entropy: A case study of the Haihe River basin in China. J Food Agri Environ, 2010, 8: 1062-1066

Open Access This article is distributed under the terms of the Creative Commons Attribution License which permits any use, distribution, and reproduction in any medium, provided the original author(s) and source are credited. 